Blocken B, Carmeliet J. 2012. A simplified numerical model for rainwater runoff on building facades: possibilities and limitations. Building and Environment 53: 59-73.

\title{
A simplified numerical model for rainwater runoff on building facades: possibilities and limitations
}

\author{
B. Blocken* ${ }^{(a)}$, J. Carmeliet ${ }^{(b, c)}$
}

(a) Building Physics and Services, Eindhoven University of Technology, P.O. box 513, 5600 MB Eindhoven, The Netherlands

(b) Chair of Building Physics, Swiss Federal Institute of Technology ETHZ, ETH-Hönggerberg, CH-8093 Zürich, Switzerland

(c) Laboratory for Building Science and Technologies, Swiss Federal Laboratories for Materials Testing and Research, Empa, Überlandstrasse 129, CH-8600 Dübendorf, Switzerland

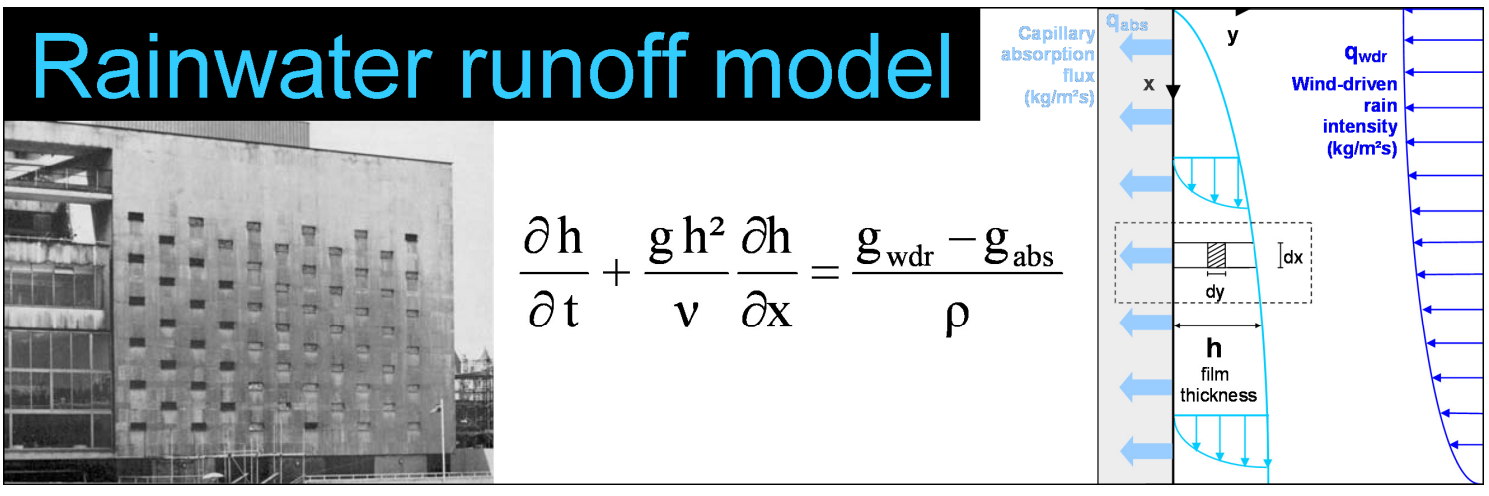

- Development, evaluation and application of simplified rainwater runoff model

- Transient model based on continuity equation and extension of Nusselt solution

- Detailed discussion of model possibilities and model limitations.

- Model can easily be implemented in 2D Heat-Air-Moisture transfer models

- Model evaluation with laboratory experiments and on-site runoff measurements

* Corresponding author: Bert Blocken, Building Physics and Services, Eindhoven University of Technology, P.O.Box 513, 5600 MB Eindhoven, the Netherlands. Tel.: +31 (0)40 247 2138, Fax +31 (0)40 2438595

E-mail address: b.j.e.blocken@tue.nl 


\title{
A simplified numerical model for rainwater runoff on building facades: possibilities and limitations
}

\author{
B. Blocken* ${ }^{(a)}$, J. Carmeliet ${ }^{(b, c)}$ \\ (a) Building Physics and Services, Eindhoven University of Technology, P.O. box 513, 5600 MB Eindhoven, \\ The Netherlands \\ (b) Chair of Building Physics, Swiss Federal Institute of Technology ETHZ, ETH-Hönggerberg, CH-8093 \\ Zürich, Switzerland \\ (c) Laboratory for Building Science and Technologies, Swiss Federal Laboratories for Materials Testing and \\ Research, Empa, Überlandstrasse 129, CH-8600 Dübendorf, Switzerland
}

\begin{abstract}
A simplified numerical model for rainwater runoff on building facades is presented, evaluated and discussed. The variation of runoff film thickness is described by a first-order hyperbolic partial differential equation. This equation is derived from the continuity equation, to which the wind-driven rain (WDR) intensity and the capillary absorption flux by the wall are added as source/sink terms, and from the adoption of the parabolic velocity profile of the Nusselt solution for a simplified representation of thin film flow. Two major model simplifications are the adoption of the Nusselt solution for (1) statistically-steady, developed films, in spite of actual wave behaviour, and for (2) transient, developing films, in spite of the actual moving contact line complexity. Both simplifications are directly related to surface tension effects. Concerning the first simplification, a selective review of the literature, including experimental laboratory data, confirms the validity of the Nusselt solution for representing the time-averaged properties of thin film flow, up to film Reynolds numbers of 1000, in spite of the actual wave behaviour. Concerning the second simplification, the runoff model is evaluated by a comparison with available on-site measurements of rainwater runoff from a building facade exposed to WDR, indicating a fair qualitative and quantitative agreement. Specific attention is given to a discussion of the possibilities and limitations of the runoff model. The runoff model can easily be integrated into $2 \mathrm{D}$ and 3D building envelope heat-air-moisture transfer (BE-HAM) models, but further research on the simplifications and assumptions of the runoff model is required.
\end{abstract}

Keywords: Wind-driven rain; driving rain; building wall; numerical simulation; wind flow; heat air moisture transfer modelling

\section{Nomenclature:}

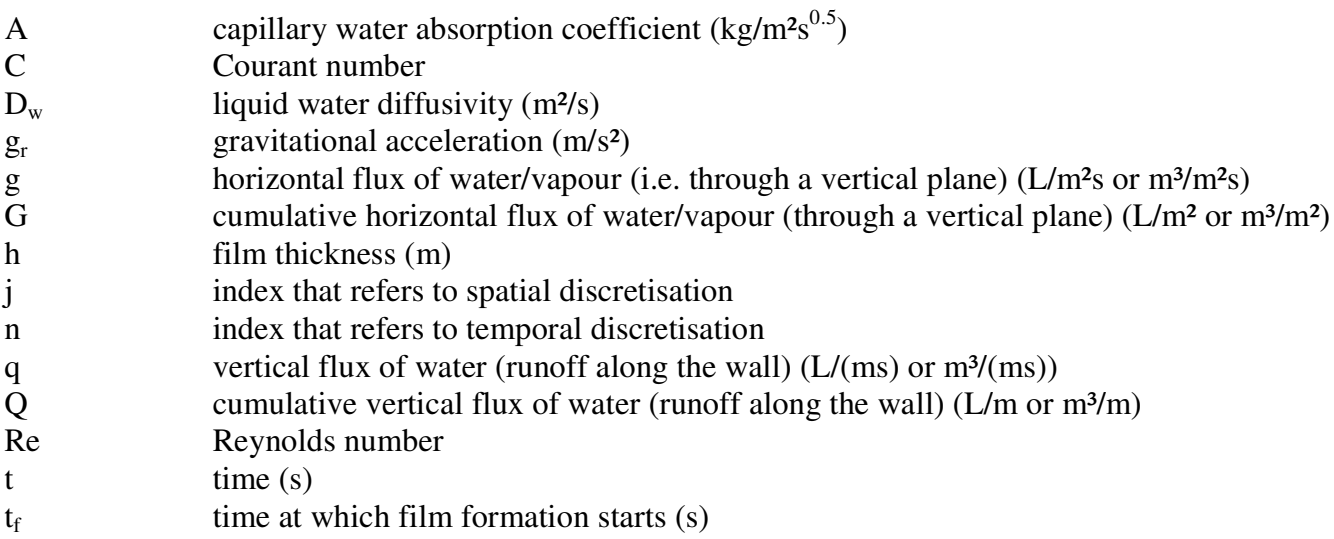

\footnotetext{
* Corresponding author: Bert Blocken, Building Physics and Services, Eindhoven University of Technology, P.O.Box 513, 5600 MB Eindhoven, the Netherlands. Tel.: +31 (0)40 247 2138, Fax +31 (0)40 2438595

E-mail address: b.j.e.blocken@tue.nl
} 


\begin{tabular}{|c|c|}
\hline $\mathrm{u}, \mathrm{v}$ & streamwise and transverse velocity components $(\mathrm{m} / \mathrm{s})$ \\
\hline $\mathrm{w}_{\mathrm{c}}$ & capillary moisture content $\left(\mathrm{kg} / \mathrm{m}^{3}\right)$ \\
\hline $\mathrm{x}, \mathrm{y}, \mathrm{z}$ & streamwise, transverse and spanwise coordinates $(\mathrm{m})$ \\
\hline$\beta$ & wall inclination $\left(90^{\circ}\right.$ for a vertical wall) \\
\hline$\Delta \mathrm{t}$ & time interval (s) \\
\hline$v$ & kinematic viscosity $\left(\mathrm{m}^{2} / \mathrm{s}\right)$ \\
\hline$\rho$ & density $\left(\mathrm{kg} / \mathrm{m}^{3}\right)$ \\
\hline$\tau$ & time $(\mathrm{s})$ \\
\hline \multicolumn{2}{|l|}{ Acronyms: } \\
\hline BE-HÄM & Building Envelope Heat-Air-Moisture \\
\hline CFD & Computational Fluid Dynamics \\
\hline CFL & Courant-Friedrichs-Lewy \\
\hline CHTC & Convective Heat Transfer Coefficient \\
\hline SF & Sharp Front \\
\hline WDR & Wind-Driven Rain \\
\hline \multicolumn{2}{|l|}{ Subscripts: } \\
\hline abs & absorption \\
\hline ave & time-averaged \\
\hline $\mathrm{B}$ & Beijer \\
\hline$f$ & film \\
\hline ker & kerosine \\
\hline loc & local \\
\hline $\max$ & maximum \\
\hline $\mathrm{N}$ & Nusselt \\
\hline sil & silicone \\
\hline W & water \\
\hline wdr & wind-driven rain \\
\hline
\end{tabular}

\section{Introduction}

Wind-driven rain (WDR) is one of the most important moisture sources affecting the hygrothermal performance and the durability of building facades (e.g. [1,2]). Consequences of its destructive properties can take many forms. Moisture accumulation in porous materials can lead to water penetration, moisture induced salt migration, discolouration by efflorescence, structural cracking due to thermal and moisture gradients, to mention just a few. WDR impact and runoff are also responsible for the appearance of other types of surface soiling patterns on facades that have become characteristic for so many of our buildings (e.g. [1,3-5]). Figure 1 illustrates the Royal Festival Hall in London, before and after a few years of atmospheric exposure. The combined effect of atmospheric deposition of pollutants and WDR on the facade leads to "white washing" and "dirt washing". At the top of the facade, the high WDR intensities rinse away the dirt ("white washing") and move it to the lower facade parts, where it is deposited ("dirt washing"). Locally, rain water runoff from window glass and sills can also cause "white washing" and "dirt washing", and it adds detail to the overall soiling pattern. Recent research on the self-cleaning action of glass combined with runoff [6] and the leaching of nanoparticles from surface coatings and biocides from facades $[7,8]$ has indicated two additional important reasons to study rainwater runoff from building facades.

Concerning the interaction between WDR and building facades, two parts of WDR research can be distinguished [2]: (1) assessment of the impinging WDR intensity (Fig. 2a) and (2) assessment of the response of the building facade to the impinging WDR (Fig. 2b). The impinging WDR intensity is the total amount of rainwater that comes into contact with the building surface. What happens at and after impact/impingement is the focus of the second part of WDR research. It comprises the study of contact and surface phenomena such as splashing, bouncing, adhesion, runoff, evaporation, absorption and the distribution of the moisture in the facade (rain penetration and wetting-drying). It also includes the wide variety of rainwater penetration mechanisms such as hydrostatic pressure, wind pressure, surface tension and gravity.

By far most WDR research in the past has focused on the first part, in which the amount and intensity of WDR across building facades was assessed by measurements (e.g. [9-14]), semi-empirical formulae (e.g. [9,1519]) and numerical simulations based on Computational Fluid Dynamics (CFD) (e.g. [20-23]). An extensive review of research on this first part of WDR research was provided by Blocken and Carmeliet [2]. The second part in WDR research however has received much less attention. While many numerical simulation studies of 
heat, air and moisture (HAM) transfer in building components have been conducted, only very few have focused in detail on WDR as a boundary condition (e.g. [24-27]). Contact and surface phenomena such as spreading, splashing and bouncing on vertical building surfaces have been studied by Couper [28] and Abuku et al. [29]. Rainwater penetration mechanisms including hydrostatic pressure, wind pressure, surface tension, gravity, etc., have been discussed by Straube [16]. In the past, also some important rainwater runoff studies were conducted (e.g. [30-37]). Although very valuable, most previous studies on rainwater runoff were (quantitative)

experimental studies or (qualitative) observational studies. Analytical rainwater runoff models were suggested by Beijer and Johansson [31], Beijer [32] and El-Shimi et al. [36]. These models assumed a constant WDR intensity and a simplified moisture absorption model, expressing the absorption flux $\mathrm{g}_{\mathrm{abs}}$ as $\mathrm{At}^{0.5}$ [31,32] (with A the capillary absorption coefficient and the time) or as a polynomial involving the same parameters [36]. The laboratory and full-scale measurements on concrete walls in Sweden by Beijer [32] indicated that the runoff fluxes down the wall were in the range of $1-10 \mathrm{~L} / \mathrm{mh}$, that the runoff velocities were in the range $25-80 \mathrm{~m} / \mathrm{h}$ $(0.007-0.022 \mathrm{~m} / \mathrm{s})$ and that the film thickness varied between 0.04 and $0.12 \mathrm{~mm}$. Hall and Kalimeris [37] provided an analytical expression for the film thickness as a function of height on the wall, WDR intensity and $\mathrm{g}_{\mathrm{abs}}$. They stated that on saturated surfaces, runoff films are normally $0.1-0.3 \mathrm{~mm}$ thick, and that the mean runoff velocity is $0.025-0.250 \mathrm{~m} / \mathrm{s}$. Note that both Beijer [32] unfortunately did not specify at which height on the wall and for which specific WDR intensity these values were obtained, which could have explained the differences with the values by Hall and Kalimeris [37].

Numerical Building Envelope Heat-Air-Moisture (BE-HAM) transfer models are generally used to analyse the hygrothermal behaviour and durability of building facades. Most BE-HAM models include WDR as a boundary condition, but generally only in a simplified way [15,17,24-27]. Processes such as rainwater runoff are generally not taken into account. The fact that runoff is generally not included in BE-HAM models is attributed to two reasons: (1) until recently, most BE-HAM models in which WDR is included were only 1D models, while runoff is essentially a 2D or 3D phenomenon, and (2) the lack of a simplified numerical runoff model that can easily be integrated into the existing BE-HAM models. To the knowledge of the authors, numerical models for rainwater runoff from building facades have not yet been developed and applied.

In the framework of the second part of WDR research and to support the further development of BE-HAM models, this paper presents a simplified numerical model for rainwater runoff from building facades. The model is represented by a first-order hyperbolic partial differential equation with the film thickness as primary variable. It is derived from the continuity equation, to which the WDR intensity and the capillary absorption flux by the wall are added as source and sink terms, and from the adoption of the parabolic velocity profile of the Nusselt solution as the film flow velocity profile. First, the Nusselt solution and its assumptions are given (section 2). Next, the transient runoff model is derived in section 3.1, and it is combined with a simplified rain water absorption model (section 3.2), after which model implementation is briefly outlined in section 3.3. Two major model simplifications are (1) the adoption of the Nusselt solution for statistically-steady, developed films, in spite of actual wave behaviour, and (2) the adoption of the Nusselt solution for transient, developing films, in spite of the actual moving contact line complexity. Both simplifications are directly related to surface tension effects, and are discussed in detail in sections 4.1 and 4.2. The model results are further analysed in section 5.1. In section 5.2, the model is used for a brief parametric analysis of runoff on the facade of a building. Finally, in section 6 , the possibilities and limitations of the runoff model are discussed.

\section{Nusselt solution}

The derivation of the Nusselt solution from the Navier-Stokes equations can be found in the literature [38]. Strictly, the Nusselt solution is only valid for the thin film flow of an isothermal Newtonian liquid with constant density $\rho$ and kinematic viscosity $\nu$ down an inclined plane (with an angle $\beta$ to the horizontal) under the action of gravity (Fig. 3). The flow is steady and parallel (laminar) and the film thickness is constant in space (no undulatory behaviour). It is assumed that the liquid surface is uncontaminated and that the air friction on the liquid surface is negligible. In addition, the spanwise gradients are assumed to be negligible, reducing the problem to 2D. The Nusselt solution is given by:

$\mathrm{u}(\mathrm{y})=\frac{\mathrm{g}_{\mathrm{r}}}{2 \mathrm{v}} \sin \beta\left(2 \mathrm{~h}_{\mathrm{N}} \mathrm{y}-\mathrm{y}^{2}\right)$

that expresses the semi-parabolic profile of the streamwise velocity $\mathrm{u}(\mathrm{y})$ in the thin laminar film, with $\mathrm{y}$ the transverse coordinate, $\mathrm{g}_{\mathrm{r}}$ the gravitational acceleration, $v$ the kinematic viscosity and $\mathrm{h}$ the film thickness. The subscript $\mathrm{N}$ refers to Nusselt solution. From Eq. (1), the film flow rate and average velocity are given by: 


$$
\begin{aligned}
& \mathrm{q}_{\mathrm{N}}=\int_{0}^{\mathrm{h}_{\mathrm{N}}} \mathrm{u}(\mathrm{y}) \mathrm{dy}=\frac{\mathrm{g}_{\mathrm{r}} \mathrm{h}_{\mathrm{N}}^{3}}{3 \mathrm{v}} \sin \beta \\
& \mathrm{u}_{\mathrm{N}}=\frac{\mathrm{q}_{\mathrm{N}}}{\mathrm{h}_{\mathrm{N}}}=\frac{\mathrm{g}_{\mathrm{r}} \mathrm{h}_{\mathrm{N}}^{2}}{3 \mathrm{v}} \sin \beta
\end{aligned}
$$

Although the assumptions for derivation of the Nusselt solution from the Navier-Stokes equations are rather strict, later in this paper we will show that Eqs. (1) to (3) are also valid to describe time-averaged undulatory film flow in the laminar and transitional film flow regime. This is important for the application to rainwater runoff on building facades. Two additional comments are made, to be used later in this paper:

1) Boundary conditions for deriviation of the Nusselt solution are:

*At $y=h$ : the kinematic equation that expresses the temporal variation of the film thickness (Eq. (4)) and the continuity of the normal and tangential stress components (see [38])

$*$ At $\mathrm{y}=0$ : the no-slip condition: Eq. (5)

$$
\frac{\partial \mathrm{h}}{\partial \mathrm{t}}+\left.\mathrm{u}\right|_{\mathrm{h}} \frac{\partial \mathrm{h}}{\partial \mathrm{x}}=\left.\mathrm{v}\right|_{\mathrm{h}}
$$

$\mathrm{u}(0)=\mathrm{v}(0)=0$

2) The Reynolds number of the film flow is defined as:

$$
\operatorname{Re}_{\mathrm{N}}=\frac{\mathrm{u}_{\mathrm{N}} \mathrm{h}_{\mathrm{N}}}{v}
$$

It is important to note that different authors investigating thin liquid film flow have used different definitions of the Reynolds number. Several authors have used Eq. (6) (e.g. [39-43]), while some others defined the Reynolds number with an additional factor 4 [44-47]. Note that the former performed experiments of film flow down a vertical tube, rather than flow along a flat plate. This difference in Reynolds number definition is due to the fact that some authors used the film thickness $\mathrm{h}_{\mathrm{N}}$ as hydraulic diameter in the definition of the Reynolds number, while others used $4 \mathrm{~h}_{\mathrm{N}}$. Care is therefore required when analysing experimental data from previous work, as performed in the next section. For clarity, all Re numbers mentioned in this paper have been expressed using the definition in Eq. (6). Re numbers from [44-47] have been converted by division by 4 .

\section{Runoff model}

\subsection{Model derivation}

Figure 4 schematically illustrates film flow down a facade, where the flow can be supplied by runoff water from higher elevations and/or by direct WDR impingement. The facade can be porous, in which case capillary absorption can draw water from the film. As opposed to the Nusselt conditions, the film thickness is not necessarily constant and the flow is not necessarily steady. The unsteadiness can be due to either a developing film (with moving film front down the wall), or to wave behaviour, or both. The continuity equation with the addition of a source term $\mathrm{g}\left(=\mathrm{g}_{\mathrm{wdr}}-\mathrm{g}_{\mathrm{abs}}\right)$, with $\mathrm{g}_{\mathrm{wdr}}$ the WDR intensity or WDR flux and $\mathrm{g}_{\mathrm{abs}}$ the absorption flux in $\mathrm{kg} / \mathrm{m}^{2} \mathrm{~s}$ is:

$$
\int_{0}^{\mathrm{h}}\left(\frac{\partial \mathrm{u}}{\partial \mathrm{x}}+\frac{\partial \mathrm{v}}{\partial \mathrm{y}}\right) \mathrm{dy}=\frac{\mathrm{g}}{\rho}=\frac{\mathrm{g}_{\mathrm{wdr}}-\mathrm{g}_{\mathrm{abs}}}{\rho}
$$

After expansion of the left-hand side: 


$$
\int_{0}^{\mathrm{h}}\left(\frac{\partial \mathrm{u}}{\partial \mathrm{x}}\right) \mathrm{dy}+\int_{0}^{\mathrm{h}}\left(\frac{\partial \mathrm{v}}{\partial \mathrm{y}}\right) \mathrm{dy}=\frac{\mathrm{g}_{\mathrm{wdr}}-\mathrm{g}_{\mathrm{abs}}}{\rho}
$$

The first term on the left-hand side can be rewritten based on differential and integral calculus:

$$
\int_{0}^{h}\left(\frac{\partial u}{\partial x}\right) d y=\frac{\partial}{\partial x} \int_{0}^{h} u d y-\left.u\right|_{h} \frac{\partial h}{\partial x}
$$

Combining Eqs. (8) and (9) yields and :

$$
\frac{\partial}{\partial x} \int_{0}^{h} u d y-\left.u\right|_{h} \frac{\partial h}{\partial x}+\left.v\right|_{h}=\frac{g_{w d r}-g_{a b s}}{\rho}
$$

Inserting the kinematic boundary condition (material line) (Eq. (4)) into Eq. (10) gives:

$$
\frac{\partial}{\partial x} \int_{0}^{h} u d y+\frac{\partial h}{\partial t}=\frac{g_{w d r}-g_{a b s}}{\rho}
$$

Inserting finally the semi-parabolic mean velocity profile (Eq. (1) with $\beta=90^{\circ}$ ) leads to:

$$
\frac{\partial \mathrm{h}}{\partial \mathrm{t}}+\frac{\mathrm{g}_{\mathrm{r}} \mathrm{h}^{2}}{v} \frac{\partial \mathrm{h}}{\partial \mathrm{x}}=\frac{\mathrm{g}_{\mathrm{wdr}}-\mathrm{g}_{\mathrm{abs}}}{\rho}
$$

Eq. (12) is a non linear, first order, hyperbolic partial differential equation with the film thickness $\mathrm{h}(\mathrm{x}, \mathrm{t})$ as primary variable.

\subsection{Source and sink terms}

For an impervious material surface, the WDR intensity constitutes the source term and film surface evaporation is the sink term. Note however that film surface evaporation was not included in the equations above. For a porous material surface, capillary absorption is added as a sink term for film flow.

The spatial and temporal distribution of WDR across a building facade can be obtained by detailed measurements or Computational Fluid Dynamics (CFD) simulations. This information can be used in the runoff model. Evaporation from the surface of the film can be taken into account by relating the convective vapour transfer coefficient to the convective heat transfer coefficient (CHTC) by the Lewis analogy [48], which is current practice in BE-HAM tools (e.g., [25-27,49-51]). For the CHTC, various correlations exist from detailed measurements (see reviews by Palyvos [52] and Defraeye et al. [53]) and CFD simulations [54,55]. In the present paper, the model is only used during rain events (high relative humidity), and evaporation is therefore considered negligible and not taken into account.

For capillary absorption, the simplified rain absorption model by Hall and Hoff [56] is used. It is based on the sharp front model in combination with a two-stage absorption process for walls wetted by WDR. Note that pressure infiltration, where wind or gravity pushes the film into the porous medium, is not considered here. The sharp front model assumes that the liquid water diffusivity $D_{w}$ is a step function, with zero value for moisture contents below the capillary moisture content $\mathrm{w}_{\mathrm{c}}$ and a constant non-zero value above $\mathrm{w}_{\mathrm{c}}$. While the validity of this model depends on the material type and while more complex models exist, the focus of this paper is on the physical and numerical aspects of rainwater runoff, rather than on moisture transfer in walls. Therefore, the simplified sharp front model is considered fit for this purpose. The first stage in the two-stage absorption process consists of WDR absorption by the wall with a constant flux boundary condition. This continues until the water content at the surface reaches the capillary moisture content $\mathrm{w}_{\mathrm{c}}$. The second stage consists of absorption of rainwater runoff by a (capillary) saturated boundary condition. In this stage, the flux exceeds the rate at which the material can absorb water, and the flux is divided into two components: a part that is absorbed and a part that runs off. Because the model by Hall and Hoff [56] provides a more complete treatment of the transition between the two stages of the absorption process, this model is adopted in this paper. . The model details and some of its limitations are outlined in Appendix 1. Only the headlines and main equations are given here. In the first stage, 
the absorption flux $g_{a b s}$ is equal to the supplied flux $g_{w d r}$, on condition the supply flux is sufficiently small, which is the case for WDR:

$\mathrm{g}_{\mathrm{abs}}=\mathrm{g}_{\mathrm{wdr}}$

When $\mathrm{w}_{\mathrm{c}}$ is reached, a water film is formed and the capillary uptake is similar to that from a liquid water surface. The time to film formation $t_{f}$ depends on the WDR intensity and on the hydraulic properties of the material [56]:

$$
t_{f}=\frac{A^{2}}{2 g_{w d r}^{2}}
$$

with A the capillary water absorption coefficient in $\mathrm{kg} / \mathrm{m}^{2} \mathrm{~s}^{0.5}$. Starting from this moment, the boundary condition switches to a capillary saturation boundary condition and the absorption flux is given by [56]:

$$
g_{a b s}=\frac{A}{2 \sqrt{\left(t-\frac{t_{f}}{2}\right)}}
$$

Note that the time $t$ in Eq. (15) is the time from the start of the wind-driven rain event. Eq. (15) provides a continuous transition of the absorbed flux from Eq. (13) to Eq. (15). This simplified rain absorption model has several limitations, including the fact that limited facade material thickness is not taken into account. More details and more information on the model simplifications are given in Appendix A.

\subsection{Model implementation}

Eq. (12) can be solved numerically in either an explicit or implicit way. For simplicity, an explicit implementation is selected here. The discretisation employs forward differencing in time and backward differencing in space (Fig. 5):

$$
\begin{aligned}
& \frac{\partial \mathrm{h}}{\partial \mathrm{t}} \approx \frac{\mathrm{h}_{\mathrm{j}}^{\mathrm{n}+1}-\mathrm{h}_{\mathrm{j}}^{\mathrm{n}}}{\Delta \mathrm{t}} \\
& \frac{\partial \mathrm{h}}{\partial \mathrm{x}} \approx \frac{\mathrm{h}_{\mathrm{j}}^{\mathrm{n}}-\mathrm{h}_{\mathrm{j}-1}^{\mathrm{n}}}{\Delta \mathrm{x}}
\end{aligned}
$$

Eq. (12) is discretised in its conservative form, where $\mathrm{h}^{3}$ is placed inside the derivative:

$$
\frac{\partial \mathrm{h}}{\partial \mathrm{t}}+\frac{\mathrm{g}_{\mathrm{r}}}{3 v} \frac{\partial \mathrm{h}^{3}}{\partial \mathrm{x}}-\frac{\mathrm{g}}{\rho}=0
$$

The coefficients $\mathrm{a}$ and $\mathrm{b}$ are introduced:

$$
a=\frac{g_{r}}{3 v} ; b_{j}^{n+1}=\frac{g_{j}^{n+1}}{\rho}
$$

The discretised equation is:

$$
\frac{h_{j}^{n+1}-h_{j}^{n}}{\Delta t^{n+1}}+a\left(\frac{\left(h_{j}^{n}\right)^{3}-\left(h_{j-1}^{n}\right)^{3}}{\Delta x_{j-1}}\right)=b_{j}^{n+1}
$$


where $n$ is the number of the time step and $j$ is the number of the position on the wall. It can be solved for $h_{j}{ }^{n+1}$. The initial film thickness is zero, therefore the initial condition is:

$$
\mathrm{t}=0 \rightarrow \mathrm{h}(\mathrm{x}, 0)=\mathrm{h}_{0}(\mathrm{x})
$$

Employing backward differencing in space, only one boundary condition needs to be applied to solve Eq. (20).

$$
\mathrm{x}=0 \rightarrow \mathrm{h}(0, \mathrm{t})=0
$$

The Courant-Friedrichs-Lewy (CFL) condition is a necessary condition for convergence for the explicit timemarching scheme:

$$
\frac{\mathrm{u}_{\mathrm{N}} \Delta \mathrm{t}}{\Delta \mathrm{x}} \leq \mathrm{C}
$$

with $\mathrm{C}$ the Courant number. In addition, both the temporal and spatial discretisation should be fine enough to yield accurate results. When a liquid film moves down a wall over previously not capillary saturated wall parts, a sudden increase in $\mathrm{g}_{\mathrm{abs}}$ occurs at the film front in the simulation. The spatial discretisation needs to be sufficiently fine to prevent numerical instabilities in this case. To evaluate this, simulations are made for $\mathrm{q}=0.1$, $0.5,1,3,5,10,20,40,100,200,500$ and $1000 \mathrm{~L} / \mathrm{mh}$. For each separate simulation, the spatial discretisation is uniform with $\Delta \mathrm{x}=0.01 \mathrm{~m}$ and the time step $\Delta \mathrm{t}$ depends on the film velocity (averaged over the film thickness) or the film flow rate (see Eq. (23)). For each simulation, a converged solution for the developing (transient) and developed (steady) film is obtained when the Courant number is lower than 0.25. In combination with Eqs. (2-3), Eq. (23) with $\mathrm{C}=0.25$ can be written as:

$$
\Delta \mathrm{t} \leq \frac{\Delta \mathrm{x}}{4}\left(\frac{3 \mathrm{v}}{\mathrm{g}_{\mathrm{r}}}\right)^{1 / 3} \mathrm{q}_{\mathrm{N}}^{-2 / 3}
$$

with $\Delta \mathrm{t}$ in $\mathrm{s}, \Delta \mathrm{x}$ in $\mathrm{m}$ and $\mathrm{q}_{\mathrm{N}}$ in $\mathrm{m}^{3} / \mathrm{ms}$. Alternatively, for $\mathrm{q}_{\mathrm{N}}$ in $\mathrm{L} / \mathrm{mh}$, it can be written as:

$$
\Delta \mathrm{t} \leq 5872 \Delta \mathrm{x}\left(\frac{3 \mathrm{v}}{\mathrm{g}}\right)^{1 / 3} \mathrm{q}_{\mathrm{N}}^{-2 / 3}
$$

When $\Delta \mathrm{x}=0.01 \mathrm{~m}, \Delta \mathrm{t}$ ranges from $2 \mathrm{~s}$ for $\mathrm{q}_{\mathrm{N}}=0.1 \mathrm{~L} / \mathrm{mh}$ to $0.0043 \mathrm{~s}$ for $\mathrm{q}_{\mathrm{N}}=1000 \mathrm{~L} / \mathrm{mh}$.

\section{Evaluation of model possibilities and limitations}

The main advantage/possibility of the runoff model derived in the previous section is that it is quite simple and can easily be implemented into existing BE-HAM models. These models should replace the simplified absorption model mentioned in section 3.2. However, the runoff model itself is based on two major simplifications. These are (1) the adoption of the Nusselt solution for statistically-steady, developed films, in spite of actual wave behaviour, and (2) the adoption of the Nusselt solution for transient, developing films, in spite of the actual moving contact line complexity. Indeed, as opposed to the Nusselt conditions, the film thickness will generally not be constant and the flow will generally not be steady. It is expected that the Nusselt solution is most violated for developing films and for films with strong undulatory (wavy) behaviour. Both above-mentioned simplifications are directly related to surface tension effects. In this section, both simplifications are discussed. The first simplification is addressed in section 4.1, based on a selective review of the literature, including experimental laboratory data. The second simplification is addressed in section 4.2, based on available on-site measurements of rainwater runoff from a building facade exposed to WDR.

\subsection{Evaluation of runoff model for statistically-steady developed films}

For statistically-steady, developed films, addressing the validity of the runoff model can be reduced to addressing the validity of the Nusselt solution. Strictly, the Nusselt solution is only applicable at very low Reynolds numbers (e.g. Re $<5$ ). At higher Reynolds numbers, experiments as well as simulations by many authors (e.g. [39-47,57]) have shown that the flow is hydrodynamically unstable. From its starting point on an 
inclined wall, the flow first behaves as a laminar flow but subsequently gains an undulatory character (Fig. 3). In many laboratory experiments in the past, this undulatory character has been reproduced in $2 \mathrm{D}$, but in reality it will often be of 3D nature and irregular due to local and irregular perturbations.

Thin-film instability has received a lot of attention in the past, especially in chemical engineering and the process industry. Lin and Wang [58] and Chang [59] have provided extensive reviews on the topic. Fig. 6 is reproduced from the work of Kapitza and Kapitza [45] to illustrate the undulatory behaviour. The figure results from the shadow method, applied to film flow down the surface of a vertical glass tube of $0.025 \mathrm{~m}$ diameter, over a height of $0.17 \mathrm{~m}$, without perturbations at the flow inlet. Both distilled water and alcohol were used. The effect of the curvature of the tube was assessed to be less than $1 \%$ of the wavelength, and the flow could therefore be considered as flow down a plane wall. The pictures show the development of the waves and their irregular character. The reason for this undulatory behaviour and its absence in the Nusselt solution (Eq. 1) is the surface tension, which, in a thin-film flow of a low-viscosity fluid and even with slight deformations of the free surface, can acquire values comparable with the forces of viscosity $[44,45]$.

In spite of the presence of waves, many authors have theoretically and experimentally confirmed that the Nusselt solution quite accurately describes the time-averaged film characteristics, such as the mean thickness and the mean velocity of the film, even though instantaneously, large deviations can occur $[40,45,46]$. Because the Nusselt theory is the basis for the model to be developed in the present paper, three important examples supporting the time-averaged validity of this theory are outlined below. These examples are selected from the very few studies that investigated the instantaneous hydrodynamic structure under the waves. Note that in all cases, the Re numbers have been recalculated to match the definition in Eq. (6).

\subsubsection{Measurements by Karimi and Kawaji [47]}

Karimi and Kawaji [47] used high-speed video photography and a photochromic dye tracer technique to measure instantaneous velocity profiles and instantaneous local film thickness in wavy falling liquid films. The test section was a vertical Pyrex tube of $2.44 \mathrm{~m}$ length and an internal diameter of $50.8 \mathrm{~mm}$. The working fluid was deodorized kerosene, with properties $\rho_{\mathrm{ker}}=755 \mathrm{~kg} / \mathrm{m}^{3}$ and $\mu_{\mathrm{ker}}=0.00143 \mathrm{~kg} / \mathrm{ms}$ [60], yielding $v_{\mathrm{ker}}=1.894 \times 10^{-6}$ $\mathrm{m}^{2} / \mathrm{s}$. The surface tension was not reported. Measurements were made at a distance of $1.5 \mathrm{~m}$ from the liquid entrance, at which the film had reached a well-developed status. Measurement sequences were taken for periods of $3 \mathrm{~s}$. Film thickness was sampled at $50 \mathrm{~Hz}$, while other flow quantities were sampled at lower frequencies (35$50 \mathrm{~Hz}$ ). Measurements were made over the Re number range 352-1637. Note that these numbers correspond to those in [47] but divided by 4 to match the Re definition in Eq. (6). The visual observations showed varying interfacial wave characteristics with downstream distance from the entrance. Measured time variations of simultaneous film thickness $\mathrm{h}$ and instantaneous (local) to time-averaged flow rate ratio $\mathrm{q}_{\mathrm{loc}} / \mathrm{q}_{\mathrm{ave}}$ are shown in Fig. 7 for two Reynolds numbers. By measuring instantaneous, local velocity profiles under the films, the authors showed that the velocity profiles can locally deviate from the parabolic Nusselt profile. Fig. 8 by Karimi and Kawaji [47] shows instantaneous profiles for three Re numbers: 585, 833 and 1319. The deviations from the Nusselt profile are limited for the lower Re numbers ( $\leq 833$, laminar and transitional wavy films), but become very pronounced for the higher Re numbers ( $\geq 1319$, turbulent wavy films). For the laminar and transitional wavy films, the velocity ratio $\mathrm{u}_{\max } / \mathrm{u}_{\mathrm{ave}}$ was very close to 1.5 (Nusselt theory). For $\operatorname{Re}=833$, the difference is only $2 \%$. In wavy turbulent films however, significant differences between the measured velocity profiles and Nusselt's profiles were found. For $\mathrm{Re}=1319$ for example, the Nusselt ratio is $13 \%$ too large. Karimi and Kawaji [47] showed that the turbulent behaviour of the liquid film depends on the degree of waviness, and not on local Reynolds number, as suggested by other authors. Many parts of the waves with $\operatorname{Re}_{\mathrm{loc}}$ as high as 1600 showed laminar behaviour, with velocity profiles very close to Nusselt's theory. On the other hand, many parts of the wavy liquid film with $\mathrm{Re}_{\mathrm{loc}}$ as low as 300 showed large deviations from Nusselt's theory.

\subsubsection{Measurements by Moran et al. [57]}

Moran et al. [57] used the same techniques as Karimi and Kawaji [47] to measure the fully-developed flow of a thin film down a $1.92 \mathrm{~m}$ long copper plate, inclined under $45^{\circ}$. The working fluid was Silicone Fluid 200 (Dow Corning), with the following properties at $22^{\circ} \mathrm{C}: \rho_{\text {sil }}=960 \mathrm{~kg} / \mathrm{m}^{3}, v_{\text {sil }}=2 \times 10^{-5} \mathrm{~m}^{2} / \mathrm{s}$ and surface tension $\gamma_{\text {sil }}=$ $2.06 \times 10^{-2} \mathrm{~N} / \mathrm{m}$. The authors describe the development of the wave structures. When the liquid entered the test section, it first exhibited a smooth, flat gas-liquid interface but after a short distance the first small and twodimensional ripples form at the interface. The ripples subsequently further developed into a defined wavy structure with large fronts and elongated tails. At about $0.6 \mathrm{~m}$ from the inlet, the $2 \mathrm{D}$ waves developed into 3D structures with large waves. Simultaneous measurements of the instantaneous velocity profiles across the wavy laminar film and axial profiles of film thickness were made at $1.3 \mathrm{~m}$ from the inlet, and for the Reynolds number range 3-55. Time-averaged values of film thickness, velocity, etc. were calculated based on 60 instantaneous values over a total sampling period of $2.8 \mathrm{~s}$. The authors found that the instantaneous velocity profiles in wavy 
films can deviate significantly from Nusselt's profile, especially under the wave crests. However, the timeaveraged measured mean film thickness was only slightly larger than Nusselt's theory (by 6.7\%, see Fig. 9a). In the experiments, the values of $\mathrm{u}_{\max } / \mathrm{u}_{\mathrm{ave}}$ range between 1.42 and 1.56 (Fig. 9a), with an overall average of 1.47, which is very close to Nusselt's theory and within the experimental uncertainty.

\subsubsection{Measurements by Ambrosini et al. [61]}

Ambrosini et al. [61] performed experiments with water falling down an inclined stainless steel flat plate of $2 \mathrm{~m}$ long and $0.6 \mathrm{~m}$ wide. Inclinations of $45^{\circ}$ and $90^{\circ}$ with respect to the horizontal plane were tested. Experiments were conducted with water at about $20-30^{\circ} \mathrm{C}$, about $50^{\circ} \mathrm{C}$ and about $70^{\circ} \mathrm{C}$, and at different Reynolds numbers. The range of Re numbers included the "classical" thresholds for the transition between the laminar-wavy and the turbulent regimes. Capacitance probes were used to collect discrete film thickness series for periods of $8.192 \mathrm{~s}$, which were further processed. To compensate for the cooling of the thin film by evaporation, compensation by a heating system was employed for the 50 and $70^{\circ} \mathrm{C}$ tests. The experimental set-up is discussed in detail in Ambrosini et al. [61]. The film thickness was measured at a distance of $1.7 \mathrm{~m}$ downstream of a metallic net used to introduce enough perturbation to get fully-developed wave conditions. Because of local non-uniformity of film flow, measurements were made at three spanwise locations along the plate. Figures $9 \mathrm{~b}-\mathrm{d}$ represent the digitised data from [61] for the experiments with the plate in vertical position. The measured mean film thickness is compared to the Nusselt value $h_{N}$. As also noted by Ambrosini et al. [61], a good agreement is found, up to a given Reynolds number at which likely the transition to turbulent flow occurs.

\subsubsection{Measurements by Beijer [32]}

Beijer [32] reported the results of laboratory tests of runoff on vertical surfaces of concrete. Unfortunately, the details of the experiment itself were not reported in his paper, which limits the value of the comparison to some extent. Beijer suggested the following equation for the time-averaged velocity of the film in $\mathrm{m} / \mathrm{s}$ :

$\mathrm{u}=13 \sqrt{\mathrm{q}}$

where $\mathrm{q}$ is the runoff rate in $\mathrm{m}^{3} /(\mathrm{ms})$. Table 1 compares the values of runoff time-averaged velocity and film thickness measured by Beijer $\left(\mathrm{u}_{\mathrm{B}}\right.$ and $\left.\mathrm{h}_{\mathrm{B}}\right)$ with those predicted by the model, which are equal to the Nusselt solution $\left(\mathrm{u}_{\mathrm{N}}\right.$ and $\left.\mathrm{h}_{\mathrm{N}}\right)$. Considering the difficult character of runoff measurements, the agreement between measurements and model results is considered very good.

\subsubsection{Range of Nusselt solution validity for statistically-steady rainwater runoff}

Both in terms of complexity and computational cost, it would be beneficial to have a runoff model for building facades that is based on the Nusselt solution and that does not take into account the surface waves. Wave behaviour occurs at time scales of a few seconds. The aim of this paper is to develop a runoff model that can accurately predict the runoff flow rate at a time scale of a minute, which is a time step considered to be small enough for BE-HAM models. Note that, although BE-HAM simulations are generally performed based on meteorological datasets with time steps of one hour, earlier research indicated that when WDR is involved, the time step needs to be decreased to at least 10 minutes $[25,62,63]$. Several earlier combined BE-HAM and WDR simulations were indeed performed with time steps of 10 minutes or 1 minute.

With the Reynolds number defined as in Eq. (6), the relationship between Re and the runoff flow rate is given by $\operatorname{Re}_{\mathrm{N}}=\mathrm{q}_{\mathrm{N}} / v$, with $\mathrm{q}_{\mathrm{N}}$ in $\mathrm{m}^{3} / \mathrm{ms}$ or $\operatorname{Re}_{\mathrm{N}}=0.278 \times 10^{-6} \mathrm{q}_{\mathrm{N}} / v$, with $\mathrm{q}_{\mathrm{N}}$ in $\mathrm{L} / \mathrm{mh}$. For water at $10^{\circ} \mathrm{C}: \operatorname{Re}_{\mathrm{N}}=$ $0.21 \mathrm{q}_{\mathrm{N}}$. This implies that even at very high flow rates, e.g. $\mathrm{q}_{\mathrm{N}}=500 \mathrm{~L} / \mathrm{mh}$, the film Reynolds numbers remain quite limited: $\operatorname{Re}_{\mathrm{N}}=106$. Later in this paper, simulations will be made to calculate runoff amounts for different reference rainfall intensities. The low Reynolds numbers together with the literature review outlined in this section suggest that the Nusselt solution can be applied to represent the statistically-steady (time-averaged) developed film flow velocity profile for rainwater runoff down a plane, smooth facade. In the next section, nonstatistically-steady, developing runoff conditions are considered.

\subsection{Evaluation of runoff model for developing films}

It is unlikely that the Nusselt solution is valid at the moving film front of developing films. Because detailed experimental laboratory data on developing films could not be found in the published literature, in this section, the entire runoff model (including Nusselt solution and simplified rain absorption model) will be evaluated by comparison with the limited on-site experimental data that have been published in the literature. While it is recognized that these experimental data are not so comprehensive that this effort could be called "model 
validation", it is - at present and with the limited amount of available experimental data - considered a valuable effort in terms of at least model evaluation.

One of the very few experimental studies that provide some quantitative information on rainwater runoff from building facades is that reported by Beijer and Johansson [31] in a Swedish report, that was also briefly summarized in the English paper by Beijer [32] in 1977. The intention of this experimental study was to provide information to explain surface soiling of facades due to rainwater runoff. For four buildings at four different locations, on-site measurements were made of impinging WDR intensities and of the resulting rainwater runoff amounts. Beijer and Johansson [31] provided the most detailed experimental data for the site at Södermalm. Measurements were made on the south facade of a $20 \mathrm{~m}$ high building. The facade exterior consists of concrete panels. The figure of the on-site measurement set-up is reproduced in Fig. 10. Also shown in this figure are drawings of the WDR and runoff gauges. WDR was measured at five heights and runoff at four heights. The building is located on a street in a central urban area, therefore the wall is somewhat sheltered from WDR. No detailed information about the building geometry and about the surrounding buildings is provided. Fig. 11a shows the measured profiles of WDR intensity at the four sites, for "intense" (thick lines) and "weak" WDR (thin lines). While Beijer and Johansson [31] reported several difficulties and problems associated with the measurements, there was one particular rain spell that was quite exceptional and also well recorded. This was the spell on $29^{\text {th }}$ of September, 1973. Beijer and Johansson [31] mentioned that "the driving rain exemplified had and this was unusual - a fairly constant and considerable intensity for over an hour". The corresponding profile for the Södermalm site is indicated in figure 11a. The measured WDR intensity, $\mathrm{g}_{\mathrm{wdr}}$, was $1 \mathrm{~mm} / \mathrm{h}$ at a height of $18.5 \mathrm{~m}$. The measured (cumulative) runoff sum $\mathrm{Q}$ at different heights at 18, 36 and $72 \mathrm{~min}$. after the start of the rain is given in Fig. 11b. Note that the symbol Q $(\mathrm{L} / \mathrm{m})$, as opposed to $\mathrm{q}(\mathrm{L} / \mathrm{mh})$, denotes the sum of all runoff water that has run down the wall in a given period of time. In the related paper, Beijer [32] mentions that, due to initial moisture content, the values of the capillary absorption coefficient for the concrete panels should be changed from the "dry" values $20-40 \mathrm{gm}^{2} \mathrm{~s}$ " to the adjusted values $7-20 \mathrm{~g} / \mathrm{m}^{2} \mathrm{~s}^{0.5}$. These data will be used for model evaluation.

Unfortunately, there is too much missing information to perform a real validation study with these experimental data. More information is needed on at least the following parameters that are important for WDR and WDR runoff studies: (1) building and environment geometry (building width, depth and geometry of surrounding buildings); (2) positions of the measurement devices along the width of the facade; (3) error estimates for the WDR and runoff measurements; (4) WDR intensity as a function of time; (5) wind speed and wind direction (for an assessment of the convective vapour transfer coefficient, which is needed to calculate the evaporation during the rain event) and (6) more detailed material properties of the concrete walls. However, as no other and more detailed quantitative information on rainwater runoff from building facades could be found, the experiments by Beijer and Johansson [31] are used for the evaluation of the numerical runoff model. Note that the term "evaluation" is used instead of "validation" due to the lack of experimental information.

In the numerical model, a 2D section of the $20 \mathrm{~m}$ high wall is implemented. The temperature is unknown but is assumed to be $10^{\circ} \mathrm{C}$. Concerning the material properties, the exact values of the capillary absorption coefficient $A$ as mentioned by Beijer [32] are used: $A=0.007$ to $0.020 \mathrm{~kg} / \mathrm{m}^{2} \mathrm{~s}^{0.5}$. Note that these reduced values, to take into account the relatively high initial moisture content of the wall at the start of the considered rain spell, are indeed lower than the typical values for concrete reported by Hall and Yau [64]: $\mathrm{A}=0.01-0.06 \mathrm{~kg} / \mathrm{m}^{2} \mathrm{~s}{ }^{0.5}$. The report [31, p. 37] seems to suggest that $\mathrm{A}=0.007 \mathrm{~kg} / \mathrm{m}^{2} \mathrm{~s}^{0.5}$ holds for the measurement height of $18.5 \mathrm{~m}$. However, it would not be realistic to use this reduced value along the entire height of the wall. The reason is the following. Since WDR is the main moisture source for the wall, and given the strong gradients in WDR intensity with height (Fig. 11a), the initial moisture content of the wall will exhibit similar strong gradients due to previous WDR spells. Therefore, when a new WDR spell starts, the time to film formation (see Eq. (14)) will be shorter at higher positions on the wall. According to Eq. (14), to take this effect into account, the value of A needs to be reduced, in such a way that A decreases with increasing height on the wall. Indeed, Eq. (15) shows that with lower A, the absorption flux decreases, which is logical because less water can be absorbed due to the high initial moisture content. For this reason, and because the report [31, p. 37] seems to suggest that $A=0.007$ $\mathrm{kg} / \mathrm{m}^{2} \mathrm{~s}^{0.5}$ holds for the measurement height of $18.5 \mathrm{~m}$, we apply a variation of A as a function of the WDR intensity. We use two different relationships between $\mathrm{A}$ and $\mathrm{g}_{\mathrm{wdr}}$ :

1) Exponential relationship: $A=0.02 * \exp \left(-1.05 * g_{w d r}\right)$, with $g_{w d r}$ taken from Fig. 11a.

2) Linear relationship between $A$ and $g_{w d r}$, with $g_{w d r}$ taken from Fig. 11a. Note that both relationships provide the maximum value of $0.02 \mathrm{~kg} / \mathrm{m}^{2} \mathrm{~s} .5$ at the lowest (driest) part of the facade, and the value of $0.007 \mathrm{~kg} / \mathrm{m}^{2} \mathrm{~s}^{0.5}$ at height $18.5 \mathrm{~m}$. This modification of reducing the time to film formation and the absorption rate by reducing the value of $\mathrm{A}$ is considered justified, because of the limitation of the absorption model in which diffusivity is not dependent on moisture content.

The spatial discretisation interval $\Delta \mathrm{x}$ is taken $0.01 \mathrm{~m}$ and the required time step $\Delta \mathrm{t}$ to limit the instabilities at the downward moving film front is $0.01 \mathrm{~s}$, which is well below the values recommended by Eq. (25), which apply for steady-state conditions. The profile of $g_{w d r}$ is determined by scaling the profile in Fig. 11a with the 
reported value $g_{w d r}=1 \mathrm{~mm} / \mathrm{h}$ at $18.5 \mathrm{~m}$ height. The model results, in terms of the (cumulative) runoff sum $Q_{\text {runoff }}$, are compared with the experimental data in Fig. 12. Considering all experimental uncertainties, the qualitative and quantitative agreement between the numerical model results and the experiments is considered quite good, for both relationships. Note that evaporation was not included in the simulation. It is considered negligible given the high relative humidity during the rain spell. Beijer and Johansson [31] also mentioned this assumption in their report.

Note that an important limitation of the simplified moisture absorption model is that it does not take limited material thickness into account. It assumes that, before and after surface saturation, the moisture front can freely penetrate into the material. For the simulations in this section, and assuming a capillary moisture content of autoclaved aerated concrete facade panels of $365 \mathrm{~kg} / \mathrm{m}^{3}$ [65], the maximum moisture front penetration depth is only $1.6 \mathrm{~mm}$. This low value is attributed to the combination of the very low capillary absorption coefficient A and the high value of the capillary moisture content $\mathrm{w}_{\mathrm{c}}$. For other materials with other moisture properties, the penetration depth can be much larger.

\section{Model application}

\subsection{Analysis of film thickness, runoff and absorption}

The numerical model results from section 4.2 are used to provide some insights in the runoff and absorption processes. The results shown in this subsection are obtained with the exponential relationship between A and $\mathrm{g}_{\mathrm{wdr}}$. Figs. 13b-d show additional numerical data obtained from the simulations in Fig. 12. Fig. 13a repeats the profile of WDR intensity. Fig. 13b illustrates the variation of the film thickness with time. Film formation only starts after about $3 \mathrm{~min}$ (see Eq. 14 with $\mathrm{A}=0.006 \mathrm{~kg} / \mathrm{m}^{2} \mathrm{~s}^{0.5}$ and $\mathrm{g}_{\mathrm{wdr}}=1.15 \mathrm{~L} / \mathrm{m}^{2} \mathrm{~h}$ at height $20 \mathrm{~m}$ ), after which the film thickness continues to grow and the film travels down the wall. Film thickness growth is most pronounced during the first 12 minutes. The maximum film thickness during the rain spell is $0.077 \mathrm{~mm}$. We also found that at about 25 minutes after the start of the rain spell, the mean velocity of the film front decreases, due to the combined effect of larger absorption rates (larger A values) and lower WDR intensity at lower parts of the wall. Note that the film does not reach the bottom part of the wall, not even after 72 minutes of uninterrupted WDR. Fig. 13c shows the (cumulative) runoff sum Q and Fig. 13d shows the (cumulative) sum of absorbed water $\mathrm{Q}_{\mathrm{abs}}$ at different time steps. As long as runoff does not occur, the boundary condition at the wall is a flux boundary condition: all WDR is taken up by absorption; $\mathrm{g}_{\mathrm{abs}}=\mathrm{g}_{\mathrm{wdr}}$. This explains the similarity between the profiles of $g_{w d r}$ and $G_{a b s}$ for the first few minutes. When runoff occurs, the boundary condition is a constant moisture content condition. The available supply of water for potential absorption is provided by both the impinging WDR and the runoff water from the higher part of the wall. The excess water - which is not absorbed - is added to the runoff sum $Q$.

\subsection{Parametric analysis}

The numerical model is used for a brief parametric analysis to provide some additional insight in the rainwater runoff process for different conditions. Given the limitations of especially the simplified rain absorption model in this paper, the parametric analysis is limited to values of the capillary water absorption coefficient A that are within the range of model evaluation as performed in section 4 ; we only investigate $\mathrm{A}=0$ and $\mathrm{A}=0.007$ $\mathrm{kg} / \mathrm{m}^{2} \mathrm{~s}^{0.5}$. The wall height is $20 \mathrm{~m}$ and for simplicity, A is taken constant along the height of the wall. In other words, the wall is dry or uniformly wet at the beginning of the rain spell. The WDR intensity during the $72 \mathrm{~min}$. rain event is constant in time and its profile (but not the absolute value) is as given in Fig. 13a. The absolute values of $g_{w d r}$ given below are those at the top of the wall at $20 \mathrm{~m}$ (see section 4.2). The results are presented as "runoff ratio" versus height. The runoff ratio is the ratio of the runoff sum $Q(\mathrm{~L} / \mathrm{m})$ at a certain position for a certain time to the WDR sum $\mathrm{G}_{\mathrm{wdr}}\left(\mathrm{L} / \mathrm{m}^{2}\right)$ that has impinged on the entire wall during that time. Note that $\mathrm{Q}$ and $\mathrm{G}_{\mathrm{wdr}}$ are both cumulative values since the beginning of the spell. The WDR intensity $\mathrm{g}_{\mathrm{wdr}}$ is varied from 0.1 to 20 $\mathrm{L} / \mathrm{m}^{2} \mathrm{~h}$, i.e. light to very intensive WDR. Figs. 14a-c show the runoff ratio for an impervious wall $(\mathrm{A}=0$ $\mathrm{kg} / \mathrm{m}^{2} \mathrm{~s}^{0.5}$ ) at three different positions in time: $\mathrm{t}=18,36$ and $72 \mathrm{~min}$. As time increases, the film will travel down the wall and the runoff ratio will increase and approach unity at the bottom of the wall. Note that the runoff ratio will actually never become equal to one, because there is always a certain amount of water that will remain stuck to the wall and that does not run down. Figs. $14 \mathrm{~d}-\mathrm{f}$ show results for a porous wall with $\mathrm{A}=0.007 \mathrm{~kg} / \mathrm{m}^{2} \mathrm{~s}^{0.5}$. Although this is a low value indicating weak capillary activity, in rain spells with $\mathrm{g}_{\mathrm{wdr}}=0.5 \mathrm{~L} / \mathrm{m}^{2} \mathrm{~h}$, even a duration of $72 \mathrm{~min}$ is not enough to cause the runoff film to reach the bottom of the wall.

Note again that the simulations in Figs. 14d-f were made with the simplified rain absorption model that does not take limited material thickness into account. It assumes that, before and after surface saturation, the moisture front can freely penetrate into the material. 


\section{Discussion of model possibilities and limitations}

It is important to mention the possibilities and especially the limitations of the runoff model presented in this paper. Many of the limitations are caused by the adopted simplifications. Two main simplifications are:

- Adoption of the Nusselt solution for statistically-steady, developed films, in spite of actual wave behaviour;

- Adoption of the Nusselt solution for transient, developing films, in spite of the actual moving contact line complexity.

The related limitations are:

- The model does not take wave formation and rivulets into account and it is not valid for turbulent film flow, i.e. for film Re numbers above 1000;

- The model cannot predict the details of the moving film front, including film front instabilities;

- The model is only a 2D model.

Additional limitations are:

- The runoff model has been developed and applied for smooth plane walls. In reality, building walls are generally rough surfaces and in general, many facade details (recessions and protrusions) will strongly complicate the runoff patterns;

- The performance of the runoff model for developing films has only been evaluated based on the limited on-site experimental data that are available in the published literature;

- The runoff model in this paper has been combined with a simplified rain absorption model. While the validity of this model depends on the material type and while more complex models exist, the focus of this paper was on the physical and numerical aspects of rainwater runoff, rather than on moisture transfer in walls. Therefore, the simplified moisture transfer model was considered fit for this purpose. Nevertheless, it is important to recognize its limitations, including the fact that limited facade material thickness is not taken into account. This model and some of its limitations are outlined in Appendix A.

- The runoff model is a 2D model, while the simplified absorption model is a 1D model. This is considered justified, for two reasons: (1) Research has shown that, in spite of the spatial variability of WDR distribution across walls and in absence of runoff, the redistribution of moisture in the plane of the wall is limited, and 1D HAM modelling is sufficiently accurate (except for very heterogeneous walls like masonry) [69]; (2) The actual 2D moisture transfer is due to the runoff itself.

Some of these limitations have been addressed in this paper.

- Concerning the adoption of the Nusselt solution for statistically-steady, developed films, in spite of actual wave behaviour, a review of the literature has shown that the Nusselt solution is a good approximation for representing the time-averaged properties of thin film flow, up to film Reynolds numbers of 1000. The relationship $\mathrm{Re}_{\mathrm{N}}=\mathrm{q}_{\mathrm{N}} / v$ implies that the Nusselt solution can thus be used up to runoff rates of $\mathrm{q}_{\mathrm{N}}=4705 \mathrm{~L} / \mathrm{mh}$, which is a very high threshold unlikely to be exceeded except for very exceptional WDR events.

- Concerning the adoption of the Nusselt solution for transient, developing films, it should be mentioned that most likely, the Nusselt solution is invalid at the moving film front. Further research is needed to investigate this in detail. In the present paper, the entire runoff model (including Nusselt solution and simplified rain absorption model) has been evaluated by comparison with the limited on-site experimental data that have been published in the literature. While it is recognized that these experimental data are not so comprehensive that this effort could be called "model validation", it is - at present and with the limited amount of available experimental data - considered a valuable effort in terms of at least model evaluation. In spite of the important model limitations, the model evaluation has shown a fairly good qualitative and quantitative agreement between model results and the experimental results, at three different time intervals during a WDR spell. In addition, it is mentioned that the model is an integral model, in which at any time, mass is conserved. It has also been shown that the calculated film thicknesses agree well with measured values (see section 4.1.4). Both observations combined suggest that also the general downward movement of the film is predicted with fairly good accuracy.

Further addressing and alleviating the model limitations will be the focus of future work. This will include, in particular:

- Abandoning the simplified rain absorption model and coupling of the runoff model with state-of-the-art BE-HAM models. This includes investigating strategies for coupling both models in an efficient way, which is important because BE-HAM models typically use meteorological datasets with hourly data, while the time steps for the runoff models are fractions of a second.

- Implementing and testing more complex runoff models that do take into account surface tension and the related undulatory behaviour and film front instabilities; 
- Validation of the runoff model and of the coupled runoff-BE-HAM model based on detailed laboratory experiments and on-site experimental data.

In spite of all these limitations, the presented runoff model also has some particular advantages. The main advantage of this model is that it is simplified and that it can be easily be integrated into 2D and 3D BE-HAM models. Note that, although 2D and 3D HAM models exist, the current state-of-the-art in BE-HAM modelling of building components exposed to WDR mainly consists of 1D modelling [24,25-27,69]. 2D and 3D BE-HAM modelling including WDR requires a runoff model. While the model presented in this paper is simplified, it is stressed that this is also the case for various other sub-models included in the state-of-the-art BE-HAM tools. Indeed, BE-HAM models are subjected to considerable uncertainties in terms of building material properties and to strong simplifications in terms of boundary conditions such as wind-driven rain [17-19,24-27] and surface convective heat and mass transfer [25-27,29,53-55]. These simplifications constitute uncertainties that may very well be larger than those incurred by the simplifications in the runoff model. Therefore, a simplified runoff model might be suitable as a supplement to the state-of-the-art BE-HAM models.

\section{Conclusions}

A simplified numerical model for rainwater runoff on building facades has been presented, evaluated and discussed. The variation of runoff film thickness is described by a first-order hyperbolic partial differential equation. This equation is derived from the continuity equation, to which the wind-driven rain (WDR) intensity and the capillary absorption flux by the wall are added as source/sink terms, and from the adoption of the parabolic velocity profile of the Nusselt solution for a simplified representation of thin film flow. Two major model simplifications are the adoption of the Nusselt solution for (1) statistically-steady, developed films, in spite of actual wave behaviour, and for (2) transient, developing films, in spite of the actual moving contact line complexity. Both simplifications are directly related to surface tension effects. Concerning the first simplification, a selective review of the literature, including experimental laboratory data, confirms the validity of the Nusselt solution for representing the time-averaged properties of thin film flow, up to film Reynolds numbers of 1000 , in spite of the actual wave behaviour. The relationship $\mathrm{Re}_{\mathrm{N}}=\mathrm{q}_{\mathrm{N}} / \mathrm{v}$ implies that the Nusselt solution can thus be used up to runoff rates of $\mathrm{q}_{\mathrm{N}}=4705 \mathrm{~L} / \mathrm{mh}$, which is a very high threshold unlikely to be exceeded except for very exceptional WDR events. Concerning the second simplification, the runoff model is evaluated by a comparison with available on-site measurements of rainwater runoff from a building facade exposed to WDR, indicating a good qualitative and quantitative agreement in terms of runoff flow rates at three different time intervals.

Specific attention has been given to discussing the possibilities and limitations of the model. The model has several important limitations, many of which are directly related to the adopted simplifications. On the other hand, the model also has some important advantages. The main advantage of this model is that it is simplified and that it can be easily be integrated into 2D and 3D BE-HAM models. Concerning model accuracy, it is important to mention that the state-of-the-art BE-HAM models contain also other simplifications that yield considerable uncertainties, namely concerning building material properties and concerning boundary conditions such as WDR and surface convective heat and mass transfer. These simplifications constitute uncertainties that may very well be larger than those incurred by the simplifications in the runoff model. Therefore, the simplified runoff model presented in this paper, in spite of its limitations, might be suitable as a supplement to the current state-of-the-art BE-HAM models.

\section{Appendix A: Simplified rain absorption model}

As outlined by Hall and Hoff [56], the capillary diffusivity $D_{w}$ of most porous materials varies so strongly with liquid content that the capillary absorption profiles are often very steep-fronted. Therefore it is often justified to represent the wetted front region by a rectangular profile. This is the so-called Sharp Front (SF) approximation, which is essentially the Green-Ampt model of soil physics [56,66-68]. The SF model allows relatively simple analytical descriptions of many wetting processes, such as wind-driven rain (WDR) under a constant WDR intensity. The basic assumption is that the wetted region can be considered as having a uniform and constant water content (i.e. the capillary water content $\mathrm{w}_{\mathrm{c}}$ ).

The first stage in the two-stage absorption process consists of WDR absorption by the wall with a constant flux boundary condition. As long as the moisture content at the wetted surface is below the capillary moisture content $\mathrm{w}_{\mathrm{c}}$, the absorption flux $\mathrm{g}_{\text {abs }}$ is equal to the supplied flux $\mathrm{g}_{\mathrm{wdr}}$, on condition the supply flux is sufficiently small, which is the case for WDR:

$\mathrm{g}_{\mathrm{abs}}=\mathrm{g}_{\mathrm{wdr}}$ 
For a constant WDR rate $\mathrm{g}_{\mathrm{wdr}}$, the cumulative amount of absorbed water at time $\mathrm{t}$ is:

$$
\mathrm{G}_{\mathrm{abs}}(\mathrm{t})=\mathrm{g}_{\mathrm{wdr}} \mathrm{t}
$$

When $\mathrm{w}_{\mathrm{c}}$ is reached, a water film is formed and the capillary uptake is similar to that from a liquid water surface. The time to film formation $t_{f}$ depends on the WDR intensity and on the hydraulic properties of the material [56]:

$$
\mathrm{t}_{\mathrm{f}}=\frac{\mathrm{A}^{2}}{2 \mathrm{~g}_{\mathrm{wdr}}^{2}}
$$

with A the capillary water absorption coefficient in $\mathrm{kg} / \mathrm{m}^{2} \mathrm{~s}^{0.5}$. Starting from this moment, the boundary condition switches to a capillary saturation boundary condition. The WDR flux is then divided into two components: a part that is absorbed and a part which is in excess, and that runs off.

At time $t_{f}$, the cumulative amount of absorbed water is:

$$
\mathrm{G}_{\mathrm{abs}}\left(\mathrm{t}_{\mathrm{f}}\right)=\mathrm{g}_{\mathrm{wdr}} \mathrm{t}_{\mathrm{f}}=\frac{\mathrm{A}^{2}}{2 \mathrm{~g}_{\mathrm{wdr}}}
$$

Hall and Hoff [56] indicate that, since SF water content profiles are always rectangular, the state of the system at $t_{f}$ is identical with that which would be obtained if the surface had been put in contact with a free water reservoir (as in a sorptivity test) at some earlier time $\tau$. The cumulative amount of absorbed water at that time is then given by [56]:

$$
\mathrm{G}_{\mathrm{abs}}(\tau)=\mathrm{A} \sqrt{\tau}
$$

Combining Eq. (A4) and Eq. (A5) yields:

$$
\tau=\frac{\mathrm{A}^{2}}{4 \mathrm{~g}_{\mathrm{wdr}}^{2}}=\frac{\mathrm{t}_{\mathrm{f}}}{2}
$$

The origin of the time scale in the SF model is therefore situated halfway between $t=0$ and $t_{f}$, The absorption flux for $\mathrm{t}>\mathrm{t}_{\mathrm{f}}$ is:

$$
\mathrm{g}_{\mathrm{abs}}=\frac{\mathrm{A}}{2 \sqrt{\left(\mathrm{t}-\frac{\mathrm{t}_{\mathrm{f}}}{2}\right)}}
$$

Some important limitations of this simplified model are mentioned:

1) The model assumes that, at the start of the rain event, the material is initially dry. If this is not the case, initial moisture content can be taken into account by lowering the capillary moisture coefficient A. This is the approach as used in this paper when comparing the model results with the experiments by Beijer and Johansson [31].

2) The model does not take limited material thickness into account. It assumes that, before and after surface saturation, the moisture front can freely penetrate into the material.

3) The model assumes that capillary absorption itself is a 1D process, perpendicular to the wall surface, while in reality, some 2D effects will be present, although these have been shown to be limited for plane homogeneous walls [69].

Further work should include coupling of the runoff model with a state-of-the-art numerical BE-HAM model to alleviate these model shortcomings. 


\section{Acknowledgements}

We thank the researchers that provided very valuable experimental data that were used in this paper for model validation and model evaluation: O. Beijer, G. Karimi, M. Kawaji, K. Moran, J. Inumari, W. Ambrosini, N. Forgione and F. Oriolo. We are grateful to R.B. White, for the permission to use his photographs in Figure 1 of this paper. We thank MSc student Jonas Norrby, for translating the valuable report of Beijer and Johansson from Swedish to English. We also thank the anonymous reviewers for their time and many valuable comments that have substantially improved the paper.

\section{References}

[1] Eldridge HJ. 1976 Common defects in buildings, HMSO, 486 p.

[2] Blocken B, Carmeliet J. 2004. A review on wind-driven rain research in building science. Journal of Wind Engineering and Industrial Aerodynamics: 92(13): 1079-1130.

[3] Franke L., Schumann I., van Hees R., van der Klugt L., Naldini S., Binda L., Baronio G., Van Balen K., Mateus J. 1998. Damage atlas: classification and analyses of damage patterns found in brick masrony, European Commission Research Report No 8, vol. 2, Fraunhofer IRB Verlag.

[4] White RB. 1967. The changing appearance of buildings. Her Majesty's Stationery Office, London, 64 p.

[5] Davidson C.I., Tang W., Finger S., Etyemezian V., Striegel M.F., Sherwood S.I. 2000. Soiling patterns on a tall limestone building: changes over 60 years, Environmental Science and Technology 34 (4): 560-565.

[6] Euvananont C, Junin C, Inpor K, Limthongkul P, Thanachayanont C. 2008. $\mathrm{TiO}_{2}$ optical coating layers for self-cleaning applications. Ceramics International 34(4): 1067-1071.

[7] Kaegi R, Ulrich A, Sinnet B, Vonbank R, Wichser A, Zuleeg S, Simmler H, Brunner S, Vonmont H, Burkhardt M, Boller M. 2008. Synthetic $\mathrm{TiO}_{2}$ nanoparticle emission from exterior facades into the aquatic environment. Environmental Pollution 156(2): 233-239.

[8] Wittmer IK, Scheidegger R, Stamm C, Gujer W, Bader HP. 2011. Modelling biocide leaching from facades. Water Research 45(11): 3453-3460.

[9] Lacy RE. Driving-rain maps and the onslaught of rain on buildings. RILEM/CIB Symp. on Moisture Problems in Buildings, Rain Penetration, Helsinki, August 16-19, Vol. 3, paper 3-4, 1965.

[10] van Mook FJR. Driving rain on building envelopes, Ph.D. thesis, Building Physics and Systems, Eindhoven University of Technology, Eindhoven University Press, Eindhoven, The Netherlands, 2002, 198 p.

[11] Tang W, Davidson CI, Finger S, Vance K. 2004. Erosion of limestone building surfaces caused by winddriven rain: 1. Field measurements. Atmospheric Environment 38(33): 5589-5599.

[12] Blocken B, Carmeliet J. 2005. High-resolution wind-driven-rain measurements on a low-rise building experimental data for model development and model validation. Journal of Wind Engineering and Industrial Aerodynamics 93(12): 905-928.

[13] Nore K, Blocken B, Jelle BP, Thue JV, Carmeliet J. 2007. A dataset of wind-driven rain measurements on a low-rise test building in Norway. Building and Environment 42(5): 2150-2165.

[14] Briggen PM, Blocken B, Schellen HL. 2009. Wind-driven rain on the facade of a monumental tower: numerical simulation, full-scale validation and sensitivity analysis. Building and Environment 44(8): 16751690.

[15] Sanders C. Heat, air and moisture transfer in insulated envelope parts: Environmental conditions. International Energy Agency, Annex 24. Final report, volume 2. Acco, Leuven, 1996.

[16] Straube JF. Moisture control and enclosure wall systems, Ph.D. thesis, Civil Engineering, University of Waterloo, Ontario, Canada, 1998, 318 p.

[17] Blocken B, Carmeliet J. 2010. Overview of three state-of-the-art wind-driven rain assessment models and comparison based on model theory. Building and Environment 45(3): 691-703.

[18] Blocken B, Deszö G, van Beeck J, Carmeliet J. 2010. Comparison of calculation methods for wind-driven rain deposition on building facades. Atmospheric Environment 44(14): 1714-1725.

[19] Blocken B, Abuku M, Nore K, Briggen PM, Schellen HL, Thue JV, Roels S, Carmeliet J. 2011. Intercomparison of wind-driven rain deposition models based on two case studies with full-scale measurements. Journal of Wind Engineering and Industrial Aerodynamics 99(4): 448-459.

[20] Choi ECC. Simulation of wind-driven rain around a building. Journal of Wind Engineering and Industrial Aerodynamics 1993; 46\&47: 721-729.

[21] Blocken, B., Carmeliet, J. 2002. Spatial and temporal distribution of driving rain on a low-rise building, Wind and Structures 5(5), 441-462.

[22] Tang W., Davidson C.I., 2004. Erosion of limestone building surfaces caused by wind-driven rain. 2. Numerical modelling. Atmospheric Environment 38(33), 5601-5609.

[23] Blocken B, Carmeliet J. 2007. Validation of CFD simulations of wind-driven rain on a low-rise building facade. Building and Environment 42(7): 2530-2548. 
[24] Künzel HM, Kiess1 K. 1997.Calculation of heat and moisture transfer in exposed building components. International Journal of Heat and Mass Transfer 40(1): 159-167.

[25] Blocken B, Roels S, Carmeliet J. A combined CFD-HAM approach for wind-driven rain on building facades. Journal of Wind Engineering and Industrial Aerodynamics 2007; 95(7): 585-607.

[26] Janssen H, Blocken B, Carmeliet J. Conservative modelling of the moisture and heat transfer in building components under atmospheric excitation. International Journal of Heat and Mass Transfer 2007; 50(5-6): 1128-1140.

[27] Abuku M, Blocken B, Roels S. 2009. Moisture response of building facades to wind-driven rain: field measurements compared with numerical simulations. Journal of Wind Engineering and Industrial Aerodynamics 97(5-6): 197-207.

[28] Couper RR. 1974. Factors affecting the production of surface runoff from wind-driven rain. 2nd International CIB/RILEM Symposium on Moisture Problems in Buildings. Rotterdam, The Netherlands, September 10-12, 1974, paper 1.1.1.

[29] Abuku M, Janssen H, Poesen J, Roels S. 2009. Impact, absorption and evaporation of raindrops on building facades. Building and Environment 44(1): 113-124.

[30] Vos BH, Tammes E. 1976. Rain penetration through the outer walls of cavity structures. CIB W40 Washington Meeting.

[31] Beijer O, Johansson A. 1977. Driving rain against external walls of concrete (Slagregn mot betongfasader). Swedish Cement and Concrete Research Institute at the Institute of Technology, Stockholm. 92 p.

[32] Beijer O. 1977. Concrete walls and weathering, RILEM/ASTM/CIB Symposium on Evaluation of the Performance of External Vertical Surfaces of Buildings, vol. 1, Otaniemi, Espoo, Finland, August 28-31 and September 1-2, pp. 67-76.

[33] Lacasse MA, O’Connor T, Nunes SC, Beaulieu P. 2003. Report from Task 6 of MEWS Project : experimental assessment of water penetration and entry into wood-frame wall specimens. Final Report, Research Report No. 133, Institute for Research in Construction, National Research Council of Canada, 308 p.

[34] Teasdale-St-Hilaire A, Derome, D. 2006. Methodology and application of simulated wind-driven rain infiltration in building envelope experimental testing, ASHRAE Transactions 112(2): 656-670.

[35] Nusselt W. 1916. Die Oberflächenkondensation des Wasserdampfes. Zeitschrift des Vereines deutscher Ingenieure. Band 60, Nr. 28, pp. 569-575.

[36] El-Shimi M, White R, Fazio P. 1980. Influence of facade geometry on weathering. Canadian Journal of Civil Engineering 7(4): 597-613.

[37] Hall C, Kalimeris AN. 1982. Water movement in porous building materials - V. Absorption and shedding of rain by building surfaces. Building and Environment 17(4): 257-262.

[38] Ruyer-Quil C, Manneville P. 1998. Modeling film flows down inclined planes. Eur. Phys. J. B 6: $277-292$.

[39] Krantz WB, Goren SL. 1971. Stability of thin liquid films flowing down a plane. Indust. Engng Chem. Fundam. 10, 91-101.

[40] Takahama H, Kato S. 1980. Longitudinal flow characteristics of vertically falling liquid films without concurrent gas flow. International Journal of Multiphase Flow 6: 203-215.

[41] Alekseenko SV, Nakoryakov VY, Pokusaev BG. 1985. Wave formation on a vertical falling liquid film. AIChE J. 31, 1446-1460.

[42] Liu J, Paul JD, Gollub JP. 1993. Measurements of the primary instabilities of film flows. Journal of Fluid Mechanics 250: 69-101.

[43] Ramaswamy B, Chippada S, Joo SW. 1996. A full-scale numerical study of interfacial instabilities in thinfilm flows. Journal of Fluid Mechanics 325: 163-194.

[44] Kapitza, P.L. 1948. Wave flow of thin layers of a viscous liquid. Zh. Eksperim. I. Teor. Fiz., Vol. 18. Translated in: Collected Papers of P.L. Kapitza, edited by D. Ter Haar, Pergamon, New York, 1965, pp. 662-689.

[45] Kapitza P.L., Kapitza S.P. 1949. Wave flow of thin layers of a viscous liquid. Zh. Eksperim. I. Teor. Fiz., Vol. 19. Translated in: Collected Papers of P.L. Kapitza, edited by D. Ter Haar, Pergamon, New York, 1965, pp. 690-709.

[46] Mudawar I, Houpt RA. Measurement of mass and momentum transport in wavy-laminar falling liquid films. International Journal of Heat and Mass Transfer 36(17): 4151-4162.

[47] Karimi G, Kawaji M. 1998. An experimental study of freely falling films in a vertical tube. Chemical Engineering Science 53(20): 3501-3512.

[48] Chilton TH, Colburn AP. 1934. Mass transfer (absorption) coefficients. Industrial and Engineering Chemistry 26:1183-1187.

[49] Hens, H. 1996. IEA Annex 24 Final Report Volume 1: Modelling, Acco Leuven, Belgium.

[50] Scheffler, G.A., 2008. Validation of hygrothermal material modelling under consideration of the hysteresis of moisture storage, Ph.D. Thesis, Dresden, University of Technology, Dresden, Germany 
[51] Steeman, HJ, Janssens, A, De Paepe, M., 2009. On the applicability of the heat and mass transfer analogy in indoor air flows. International Journal of Heat and Mass Transfer, 52: 1431-1442.

[52] Palyvos JA. 2008. A survey of wind convection coefficient correlations for building envelope energy systems' modelling. Applied Thermal Engineering 28(8-9): 801-808.

[53] Defraeye T, Blocken B, Carmeliet J. 2010. Convective heat transfer coefficients for exterior building surfaces: Existing correlations and CFD modelling. Energy Conversion and Management 52(1): 512-522.

[54] Blocken B, Defraeye T, Derome D, Carmeliet J. 2009. High-resolution CFD simulations of forced convective heat transfer coefficients at the facade of a low-rise building. Building and Environment 44(12): 2396-2412.

[55] Defraeye T, Blocken B, Carmeliet J. 2010. CFD analysis of convective heat transfer at the surfaces of a cube immersed in a turbulent boundary layer. International Journal of Heat and Mass Transfer 53(1-3): 297-308.

[56] Hall C, Hoff WD. 2002. Water transport in brick, stone and concrete. Spon Press, London and New York.

[57] Moran K, Inumaru J, Kawaji M. 2002. Instantaneous hydrodynamics of a laminar liquid film. International Journal of Multiphase Flow 28: 731-755.

[58] Lin SP, Wang CY. 1985. Modeling wavy film flows. In Encyclopedia of Fluid Mechanics (Ed. Chermenmisinoff NP), Vol. 1, pp. 931-951.

[59] Chang HC. 1994. Wave evolution on a falling film. Annual Reviews of Fluid Mechanics 26: 103-136.

[60] Personal communication with M. Kawaji, 31 July 2010.

[61] Ambrosini W, Forgione N, Oriolo F. 2002. Statistical characteristics of a water film falling down a flat plate at different inclinations and temperatures. International Journal of Multiphase Flow 28: 1521-1540.

[62] Blocken B, Carmeliet J. 2007. On the errors associated with the use of hourly data in wind-driven rain calculations on building facades. Atmospheric Environment 41(11): 2335-2343.

[63] Blocken B, Carmeliet J. 2008. Guidelines for the required time resolution of meteorological data for winddriven rain calculations on buildings. Journal of Wind Engineering and Industrial Aerodynamics 96(5): 621-639.

[64] Hall C, Yau MHR. 1987. Water movement in porous building materials - IX. The water absorption and sorptivity of concretes. Building and Environment 22(1): 77-82.

[65] Qiu X, Haghighat F, Kumaran MK. 2003. Moisture transport across interfaces between autoclaved aerated concrete and mortar. NRCC-46411 report.

[66] Green WH, Ampt GA. 1911. Studies on soil physics. Part 1. The flow of air and water through soils. Journal of Agricultural Sciene 4: 1-24.

[67] Philip JR. 1969. Theory of infiltration. Advances in Hydrosciences 5: 215-296.

[68] Marshall TJ, Holmes JW, Rose CW. 1996. Soil physics, $3^{\text {rd }}$ Edition, Cambridge University Press.

[69] Janssen H, Carmeliet J. 2006. Hygrothermal simulation of masonry under atmospheric excitation. In: Fazio et al. (Eds.), Research in Building Physics and Building Engineering, Taylor \& Francis, London, pp. 77-82. 


\section{TABLE}

Table 1. Runoff rate and the related time-averaged film velocity $u_{B}$ and film thickness $h_{B}$ as measured by Beijer [32] and $\mathrm{u}_{\mathrm{N}}$ and $\mathrm{h}_{\mathrm{N}}$ as predicted by the numerical model (= Nusselt solution).

\begin{tabular}{cccccc}
\hline $\begin{array}{c}\mathrm{q}_{\text {runoff }} \\
(\mathrm{L} / \mathrm{mh})\end{array}$ & $\begin{array}{c}\mathrm{q}_{\mathrm{runoff}} \\
\left(\mathrm{m}^{3} / \mathrm{ms}\right)\end{array}$ & $\begin{array}{c}\mathrm{u}_{\mathrm{B}} \\
(\mathrm{m} / \mathrm{s})\end{array}$ & $\begin{array}{c}\mathrm{u}_{\mathrm{N}} \\
(\mathrm{m} / \mathrm{s})\end{array}$ & $\begin{array}{c}\mathrm{h}_{\mathrm{B}} \\
(\mathrm{mm})\end{array}$ & $\begin{array}{c}\mathrm{h}_{\mathrm{N}} \\
(\mathrm{mm})\end{array}$ \\
\hline 1 & $2.8 \mathrm{E}-07$ & 0.007 & 0.006 & 0.041 & 0.048 \\
10 & $2.8 \mathrm{E}-06$ & 0.022 & 0.027 & 0.128 & 0.104 \\
\hline
\end{tabular}




\section{FIGURES}
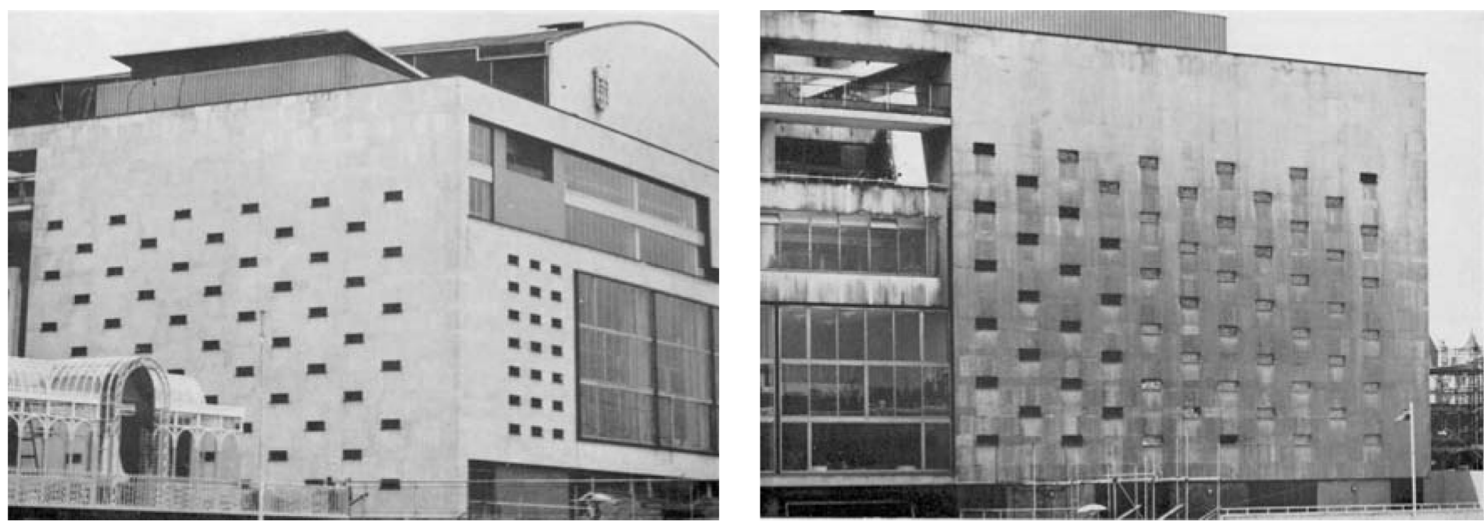

Figure 1: Royal Festival Hall, London, before and after a few years of exposure to atmospheric pollution and wind-driven rain deposition and runoff across the facade (figure from White 1967, reproduced with permission).

(a)

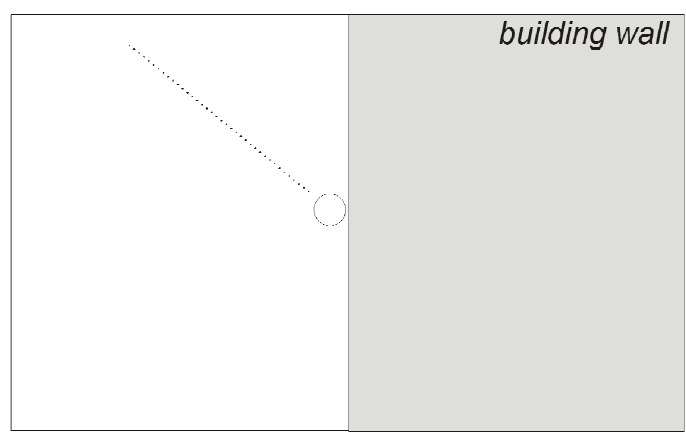

(b)

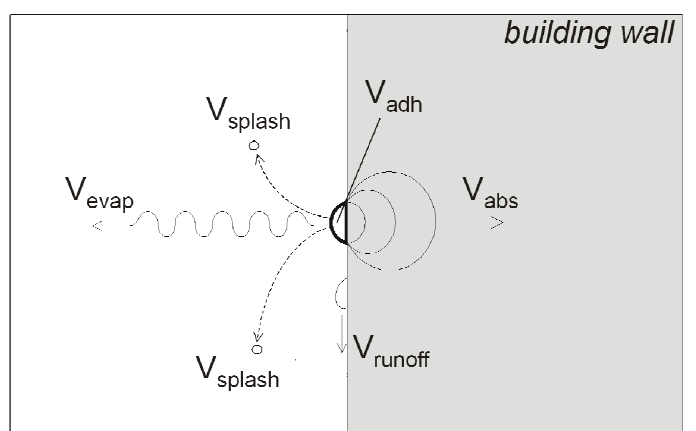

Figure 2: Schematic representation of the two parts in wind-driven rain research: (a) assessment of the impinging wind-driven rain intensity (before rain impact) and (b) assessment of the response of the wall (at and after rain impact).

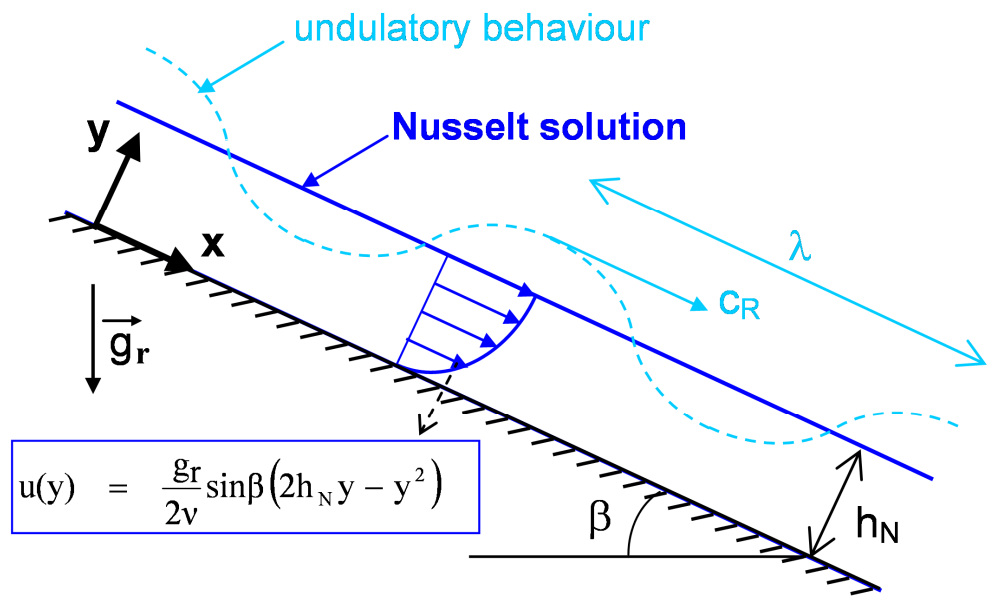

Figure 3: Schematic representation of thin film runoff down an inclined wall. Note: figure not to scale. 


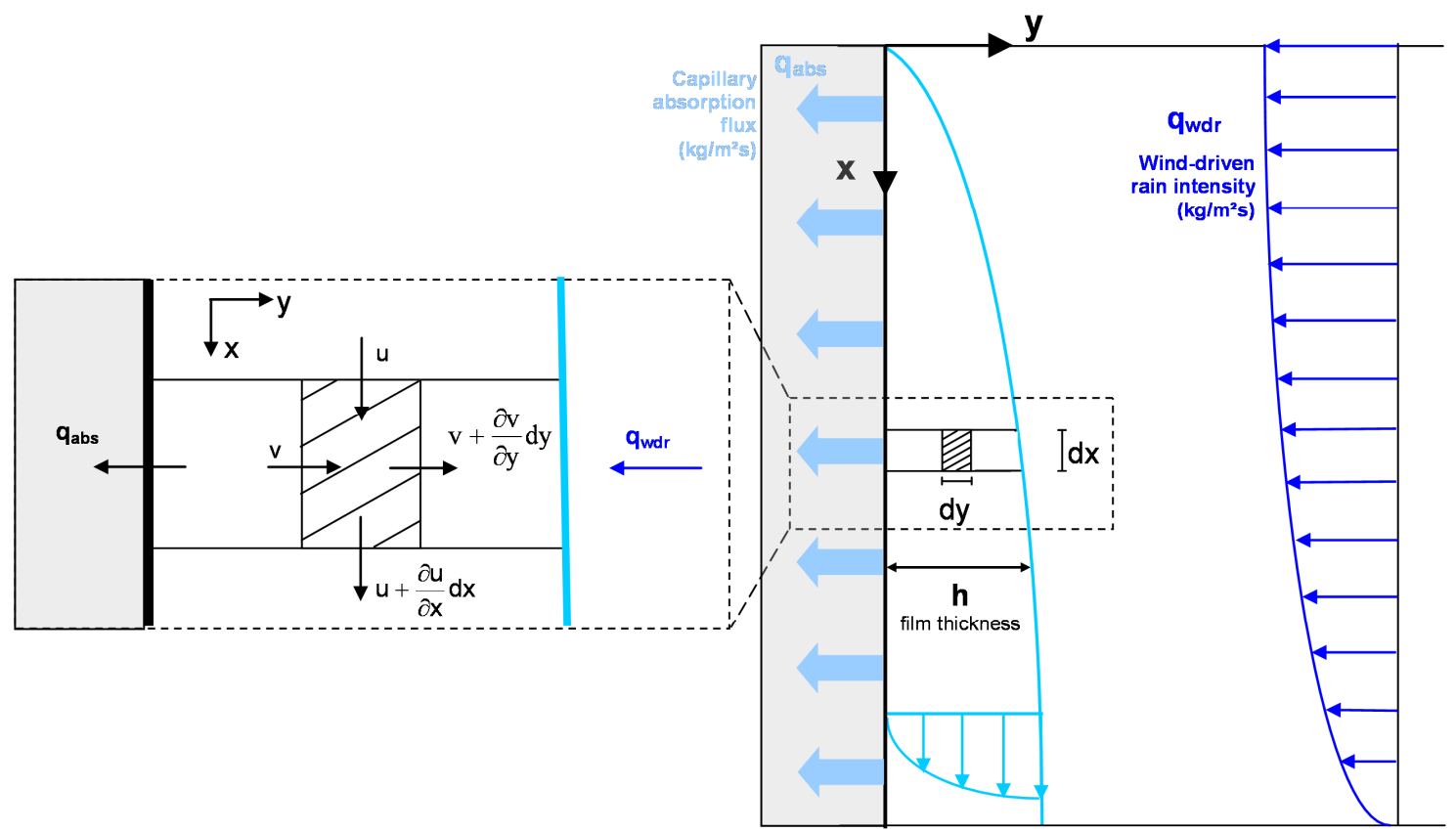

Figure 4. Schematic presentation and symbols for thin film runoff along a vertical wall with the wind-driven rain intensity and the capillary absorption flux as source and sink.

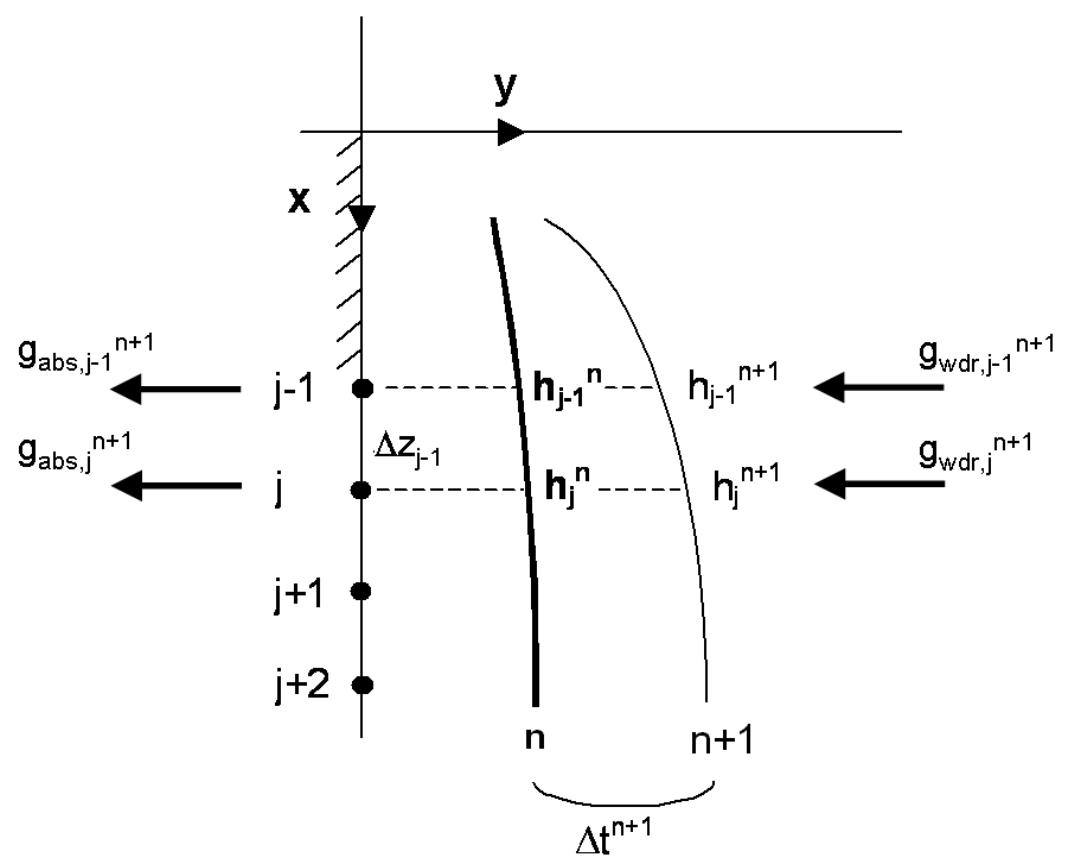

Figure 5. Discretisation of the film flow equation in space and time. 


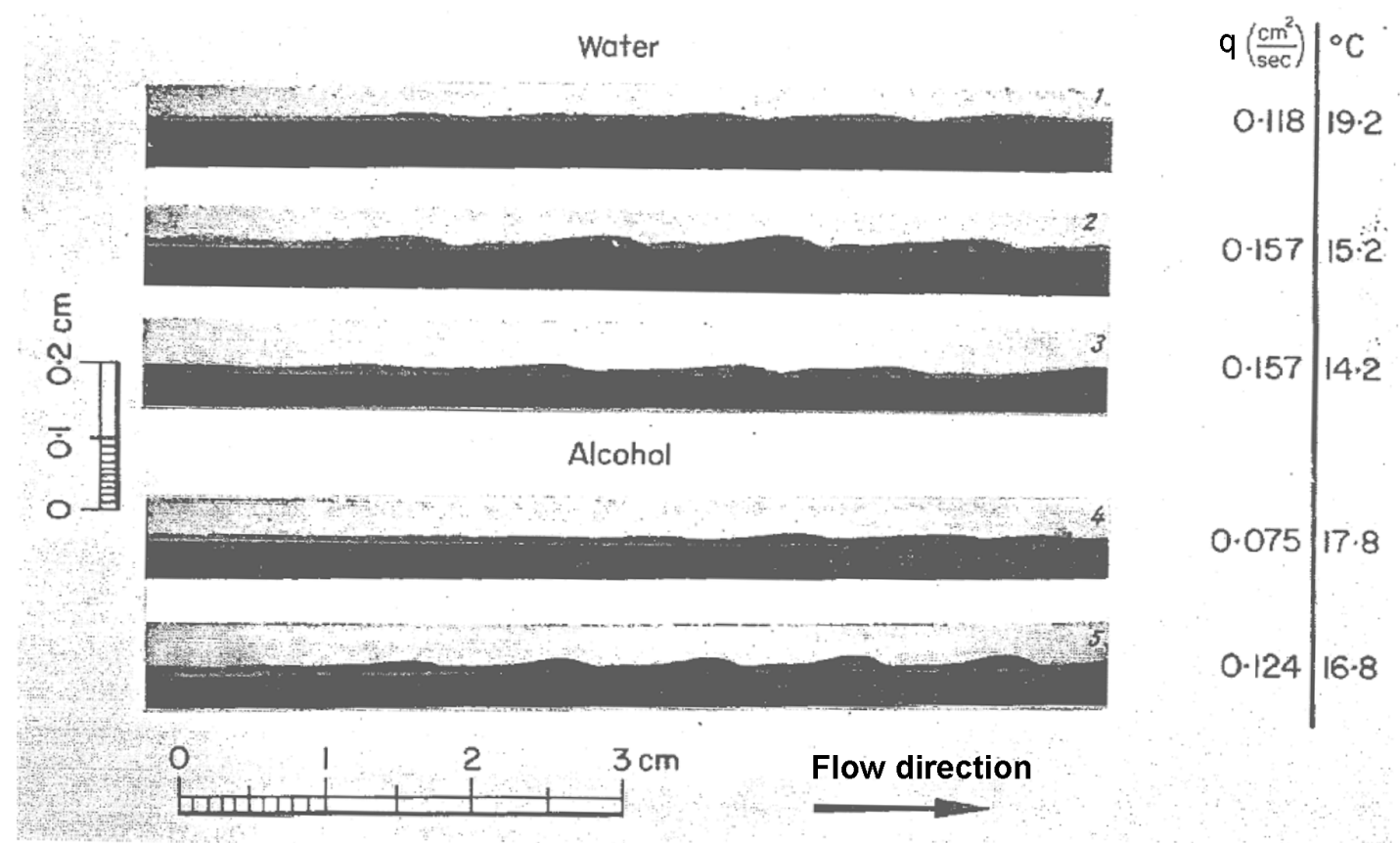

Figure 6: Shadow method illustration of undulatory behaviour of thin film water flow down the surface of a vertical glass tube, for different flow rates and temperatures (from [45]). 

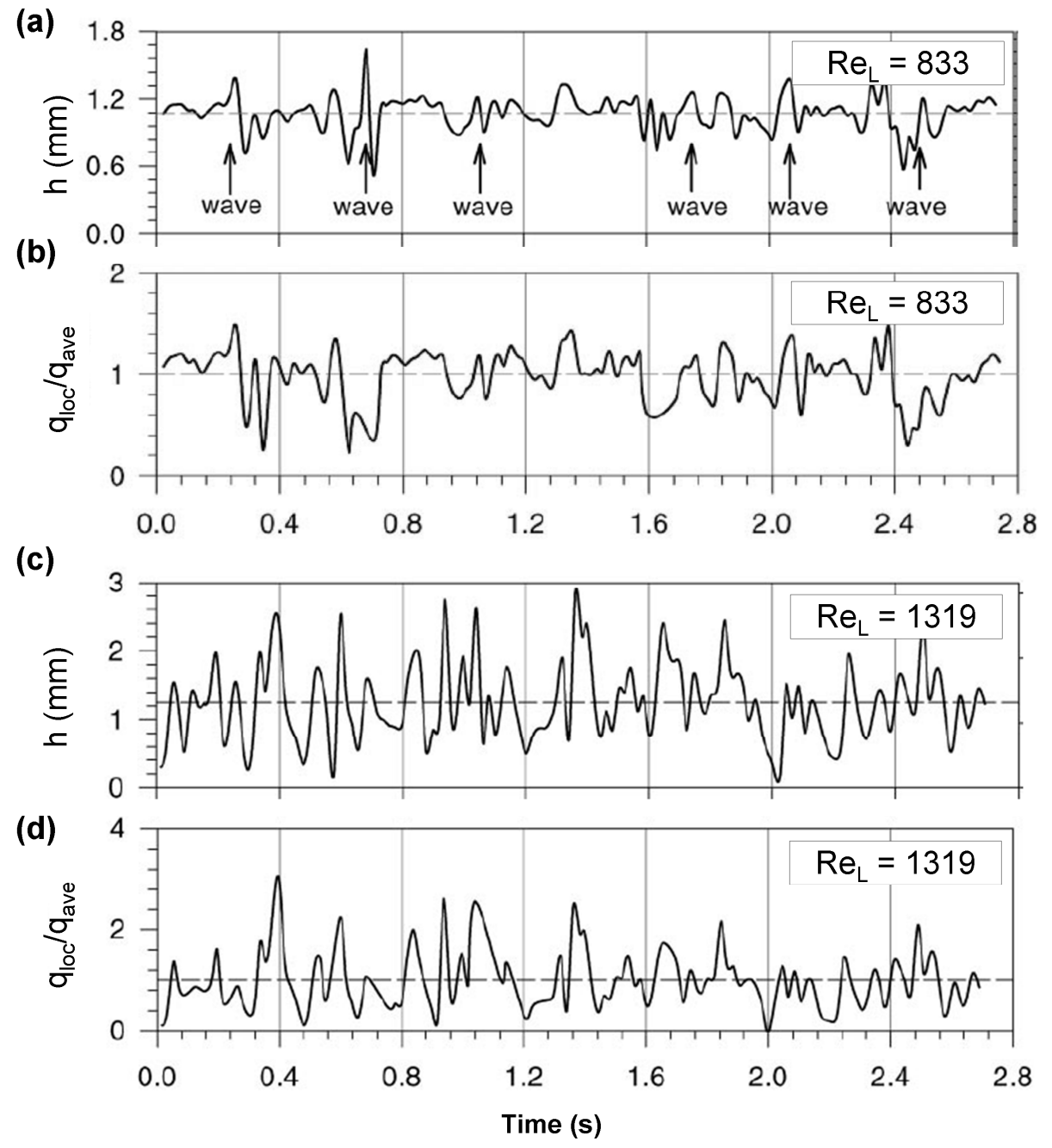

Figure 7: Instantaneous measurement data of film thickness and ratio of local to average flow rate for liquid Reynolds numbers 833 and 1319 (from [47]). 
(a)

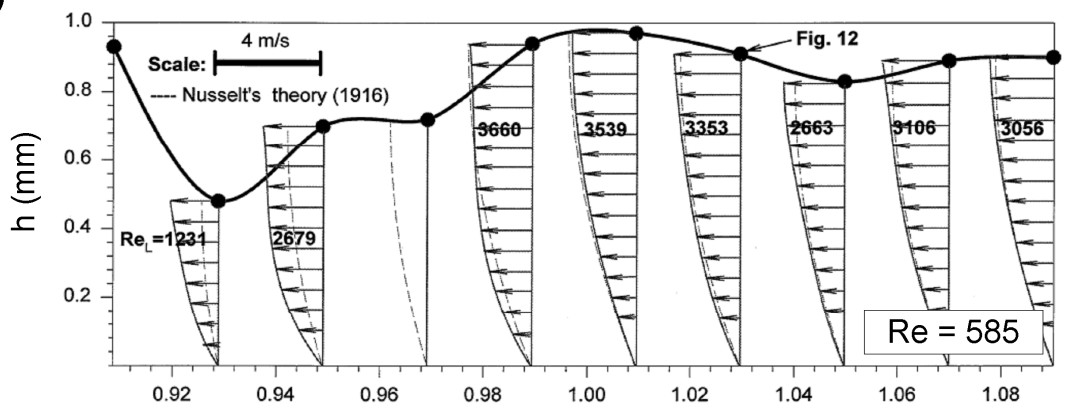

(b)

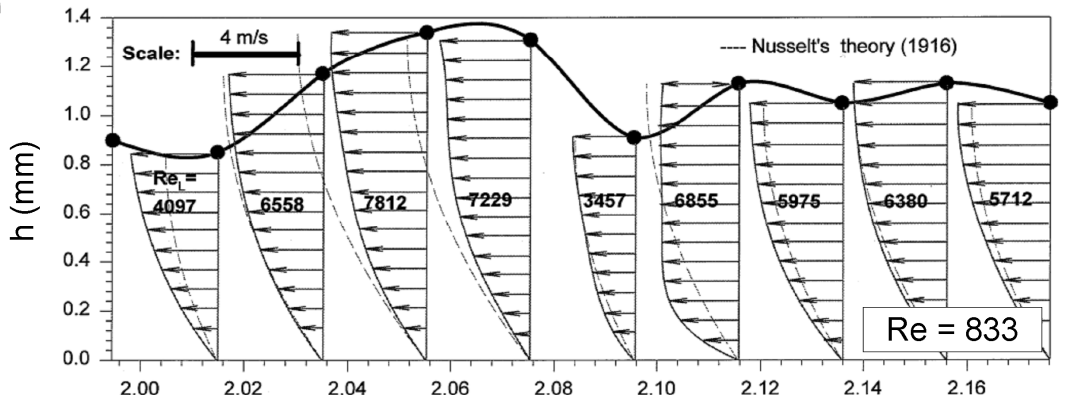

(c)

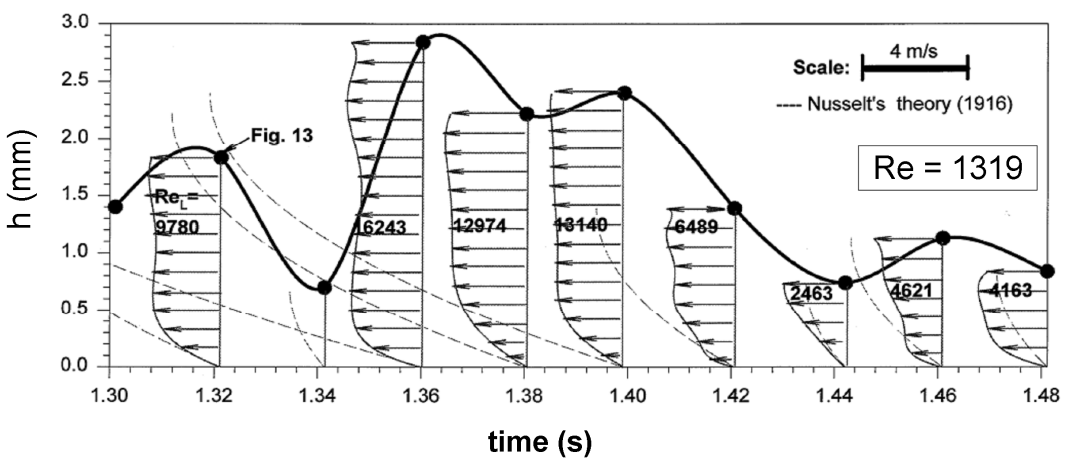

Figure 8: Instantaneous experimental velocity profiles of film flow down the surface of a vertical tube, for liquid Reynolds numbers 585, 833 and 1319 (from [47]). 

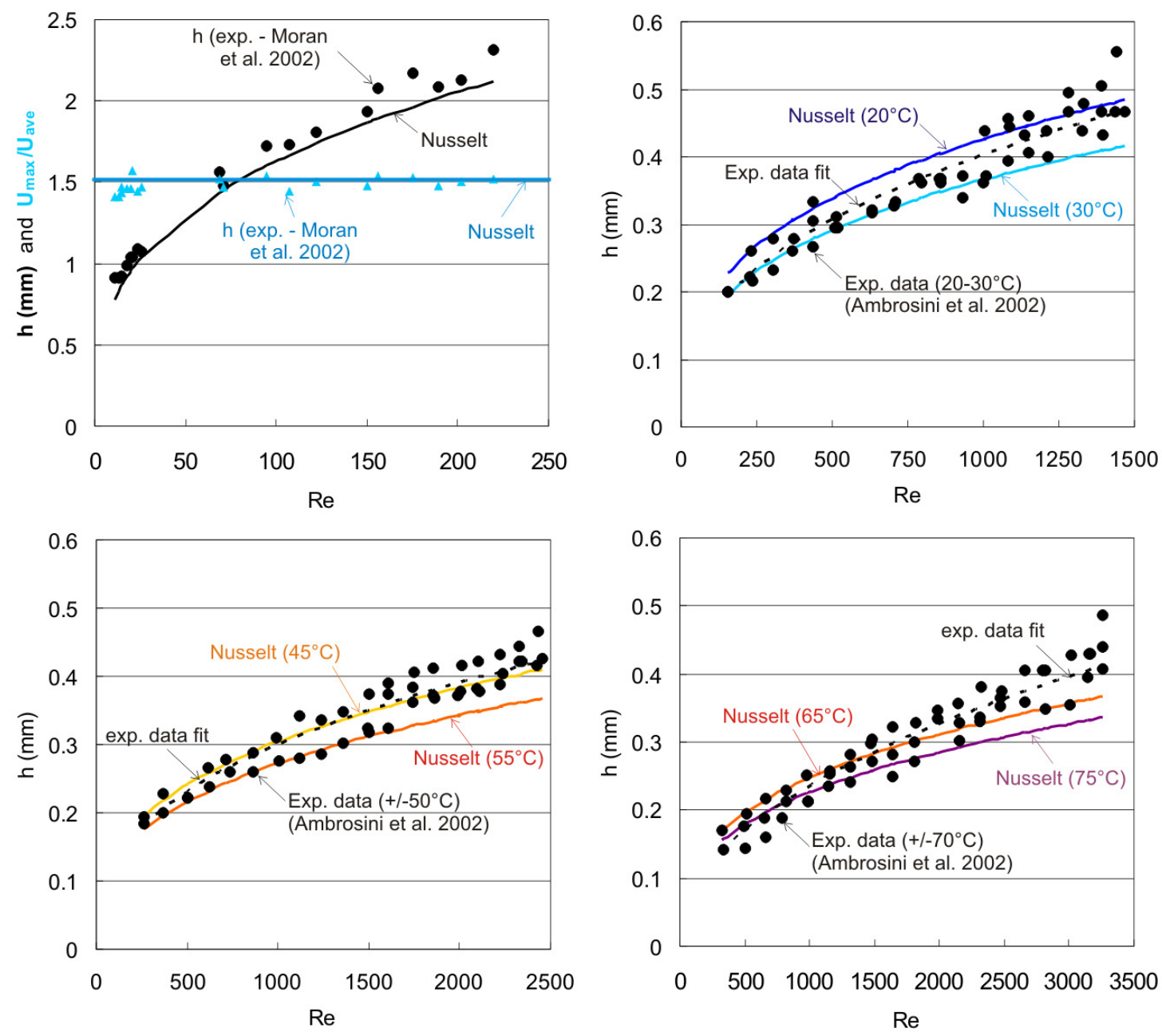

Figure 9: (a) Comparison between the experimental results of Moran et al. [57] and the Nusselt solution, for the mean film thickness $\mathrm{h}(\mathrm{mm})$ and the velocity ratio $\mathrm{u}_{\max } / \mathrm{u}_{\mathrm{ave}}$. (b-d) Comparison between the experimental results for the mean film thickness $\mathrm{h}(\mathrm{mm})$ of Ambrosini et al. [61] and the Nusselt solution, for three different water temperatures. 
(a)

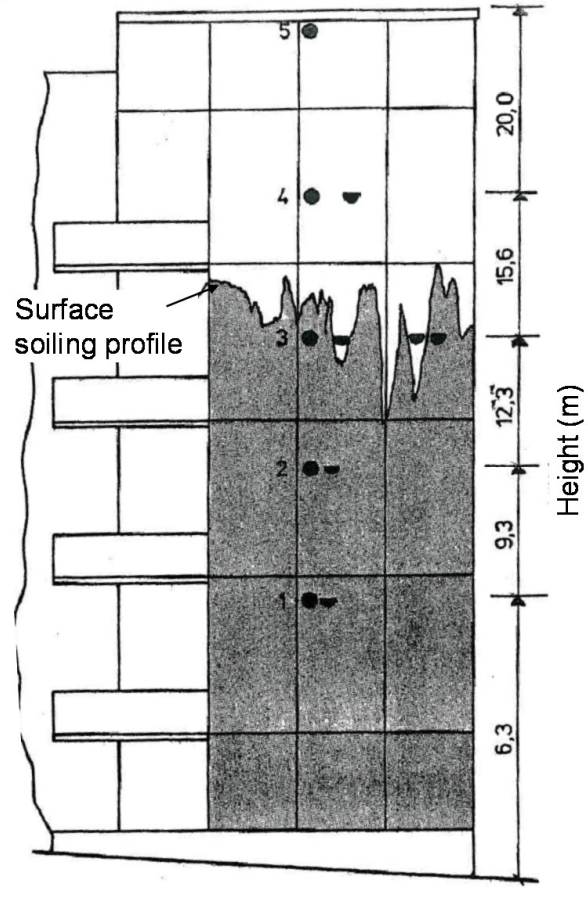

(b)

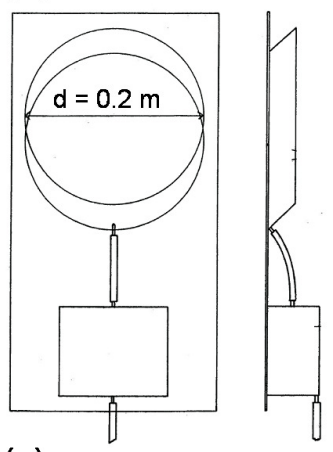

(c)

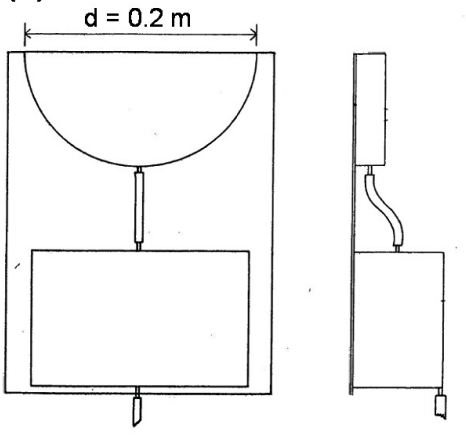

Figure 10. (a) Schematic representation of facade and measurement positions of wind-driven rain gauges (circular symbols) and runoff gauges (half-circular symbols) The surface soiling pattern at the facade is also indicated. (b) Front and side view of wind-driven rain gauge; (c) Front and side view of runoff gauge. (Figures from [31]).

(a) wind-driven rain (\%)

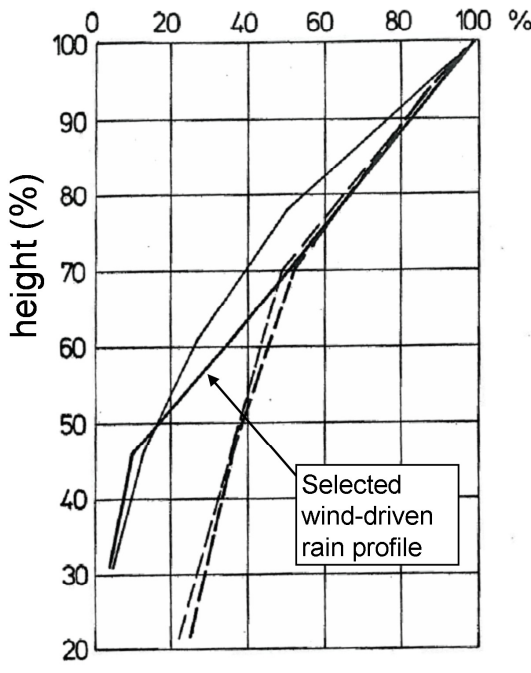

(b)

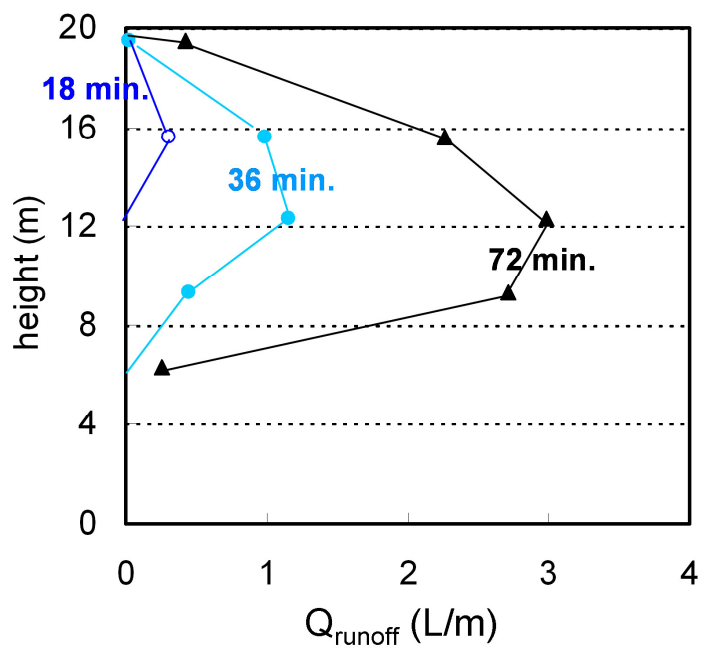

Figure 11. Measurement results: (a) Relative wind-driven rain intensity as a function of height (from [31]) with indication of selected wind-driven rain profile for the numerical simulations; (b) Runoff sum as a function of height at three different time intervals from the start of the rain spell: $18 \mathrm{~min} ., 36 \mathrm{~min}$. and $72 \mathrm{~min}$. 
(a)

\begin{tabular}{ll} 
measured at $18 \mathrm{~min}$. \\
& measured at $36 \mathrm{~min}$. \\
& measured at $72 \mathrm{~min}$. \\
\hline & simulated at $18 \mathrm{~min} .\left(\mathrm{g}_{\mathrm{wdr}}=1 \mathrm{~L} / \mathrm{m}^{2} \mathrm{~h}\right)$ \\
\hline & simulated at $36 \mathrm{~min} .\left(\mathrm{g}_{\mathrm{wr}}=1 \mathrm{~L} / \mathrm{m}^{2} \mathrm{~h}\right)$ \\
& simulated at $72 \mathrm{~min} .\left(\mathrm{g}_{\mathrm{wdr}}=1 \mathrm{~L} / \mathrm{m}^{2} \mathrm{~h}\right)$
\end{tabular}

(b)

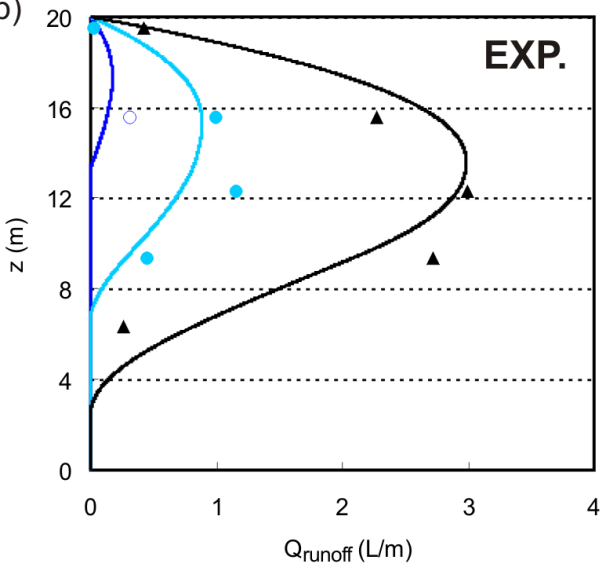

(c)

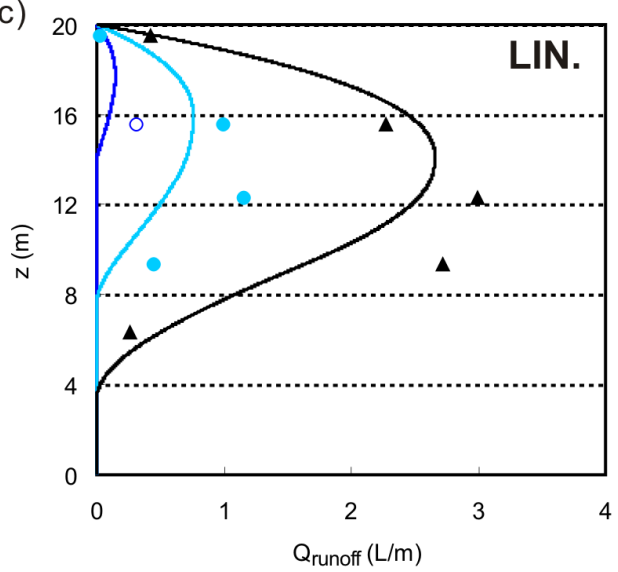

Figure 12. Comparison of numerical and experimental results for the runoff sum at 18,36 and 72 minutes after the start of the rain, for (b) an exponential and (c) a linear relationship between $\mathrm{A}$ and $\mathrm{g}_{\mathrm{wdr}}$.

(a)

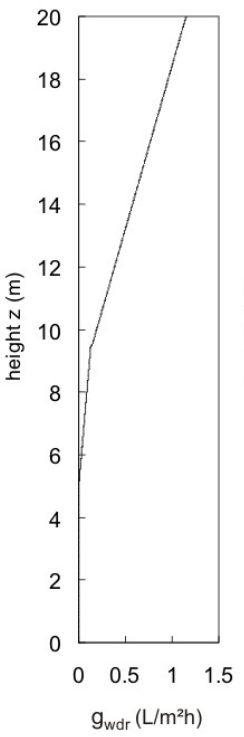

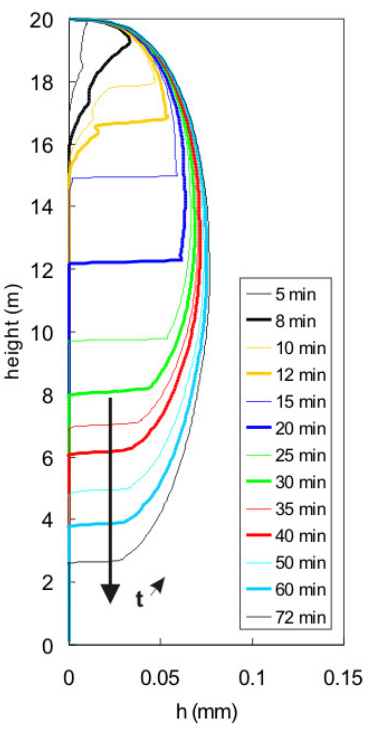

(c)

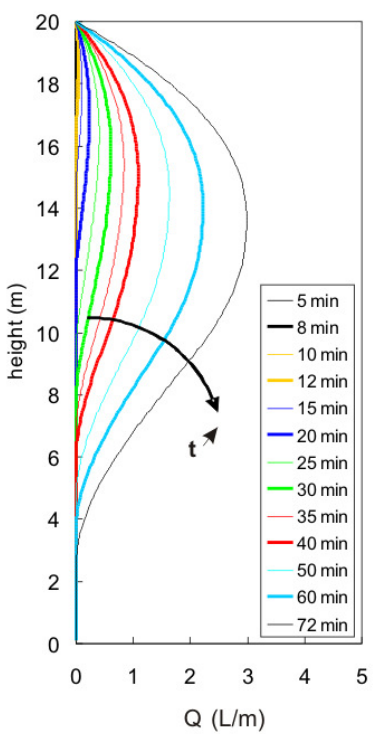

(d)

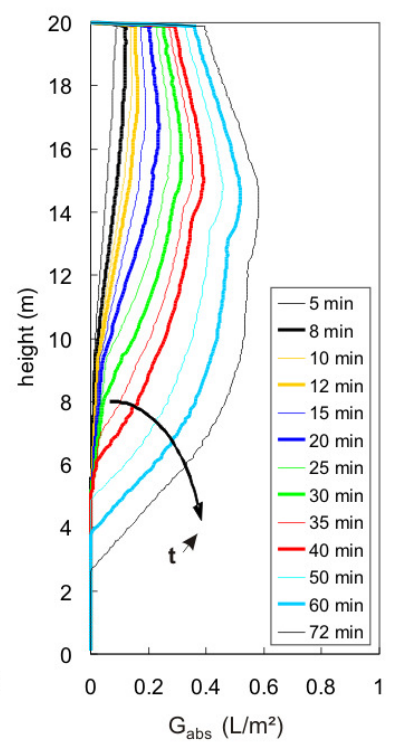

Figure 13. (a) Wind-driven rain intensity during the 72 min. rain event. (b-d) Corresponding numerical results for the $20 \mathrm{~m}$ high wall at different time steps, for (b) film thickness; (c) runoff sum and (d) sum of absorbed water. 
(a)

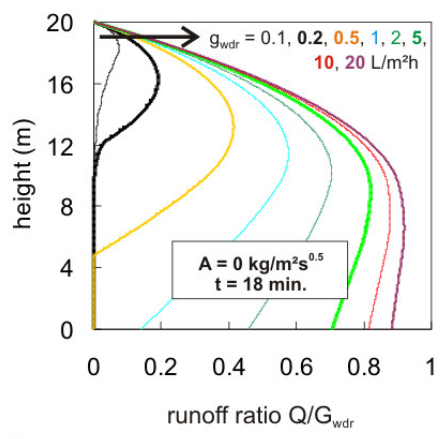

(d)

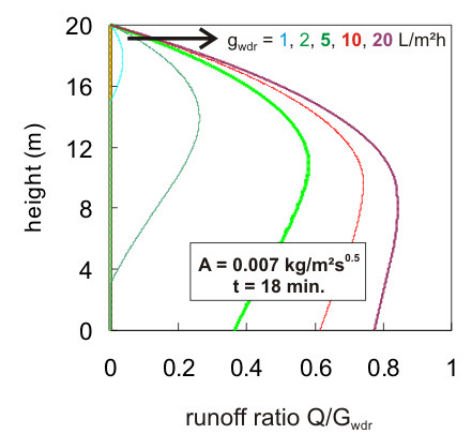

(b)

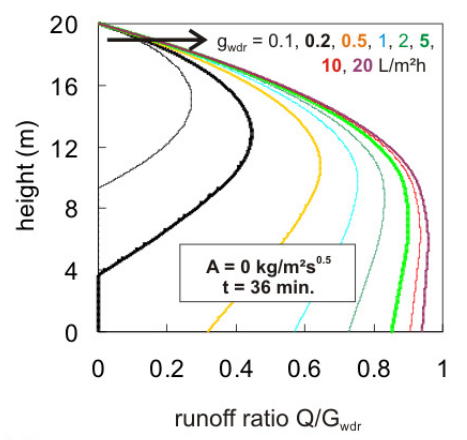

(e)

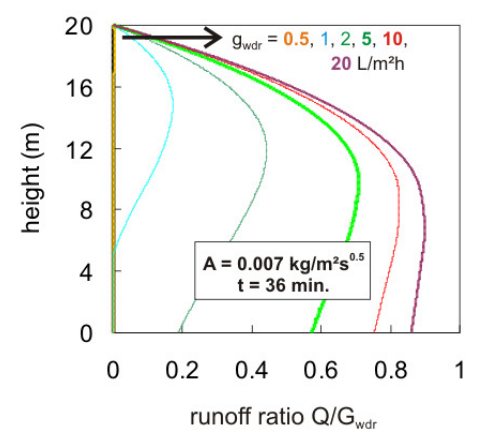

(c)

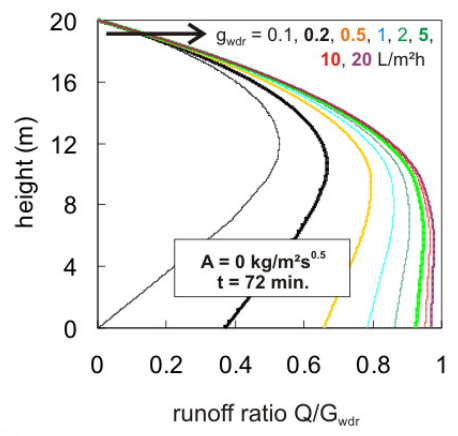

(f)

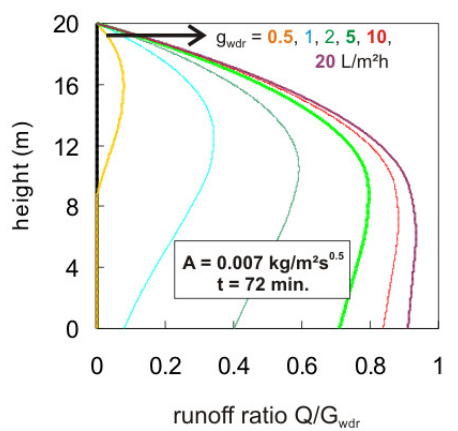

Figure 14. Parametric analysis: (a-c) Runoff ratio versus height for $A=0 \mathrm{~kg} / \mathrm{m}^{2} \mathrm{~s}^{0.5}$ (impervious wall), with the wind-driven rain intensity $g_{w d r}$ as parameter. (d-f) Same, for $A=0.007 \mathrm{~kg} / \mathrm{m}^{2} \mathrm{~s}^{0.5}$. 